OPEN ACCESS

Edited by:

Inmaculada Maria

Gonzalez-Gonzalez,

University of Central Lancashire,

United Kingdom

Reviewed by:

Camilla Bellone,

Université de Genève, Switzerland

Maria Vincenza Catania,

Istituto di Scienze Neurologiche

(CNR), Italy

${ }^{*}$ Correspondence:

Ada Ledonne

adaledonne@gmail.com

Nicola Biagio Mercuri mercurin@med.uniroma2.it

Received: 24 May 2018 Accepted: 04 September 2018 Published: 01 October 2018

Citation:

Ledonne $A$ and Mercuri NB (2018) mGluR1-Dependent Long Term Depression in Rodent Midbrain

Dopamine Neurons Is Regulated by Neuregulin 1/ErbB Signaling.

Front. Mol. Neurosci. 11:346. doi: 10.3389/fnmol.2018.00346

\section{mGluR1-Dependent Long Term Depression in Rodent Midbrain Dopamine Neurons Is Regulated by Neuregulin 1/ErbB Signaling}

\author{
Ada Ledonne ${ }^{1 *}$ and Nicola Biagio Mercuri ${ }^{1,2 *}$ \\ ${ }^{1}$ Department of Experimental Neuroscience, IRCCS Santa Lucia Foundation, Rome, Italy, ${ }^{2}$ Department of Systems Medicine, \\ University of Rome Tor Vergata, Rome, Italy
}

Increasing evidence demonstrates that the neurotrophic factor Neuregulin 1 (NRG1) and its receptors, ErbB tyrosine kinases, modulate midbrain dopamine (DA) transmission. We have previously reported that NRG1/ErbB signaling is essential for proper metabotropic glutamate receptors 1 (mGluR1) functioning in midbrain DA neurons, thus the functional interaction between ErbB receptors and mGluR1 regulates neuronal excitation and in vivo striatal DA release. While it is widely recognized that mGluR1 play a pivotal role in long-term modifications of synaptic transmission in several brain areas, specific mGluR1-dependent forms of synaptic plasticity in substantia nigra pars compacta (SNpc) DA neurons have not been described yet. Here, first we aimed to detect and characterize mGluR1-dependent glutamatergic long-term depression (LTD) in SNpc DA neurons. Second, we tested the hypothesis that endogenous ErbB signaling, by affecting mGluR1, fine-tunes glutamatergic synaptic plasticity in DA cells. We found that either pharmacological or synaptic activation of mGluR1 causes an LTD of AMPARmediated transmission in SNpc DA neurons from mice and rat slices, which is reliant on endogenous NRG1/ErbB signaling. Indeed, LTD is counteracted by a broad spectrum ErbB inhibitor. Moreover, the intracellular injection of pan-ErbB- or ErbB2 inhibitors inside DA neurons reduces mGluR1-dependent LTD, suggesting an involvement of ErbB2/ErbB4-containing receptors. Interestingly, exogenous NRG1 fosters LTD expression during minimal mGluRI activation. These results enlarge our cognizance on mGluR1 relevance in the induction of a novel form of long-term synaptic plasticity in SNpc DA neurons and describe a new NRG1/ErbB-dependent mechanism shaping glutamatergic transmission in DA cells. This might have important implications either in DA-dependent behaviors and learning/memory processes or in DA-linked diseases.

Keywords: neuregulin 1, ErbB signaling, group 1 metabotropic glutamate receptors (mGluRI), synaptic plasticity, LTD, dopamine, substantia nigra

\section{INTRODUCTION}

Neuregulins (NRGs) are a family of epidermal growth factor (EGF)-related proteins acting as neurotrophic and differentiation agents. Besides being critically involved in the development of the central nervous system (CNS), increasing evidence demonstrates that NRGs represent important neuromodulators in the adult brain. NRGs are encoded by six genes (NRG1-NRG6), each 
producing numerous isoforms, all expressing an EGF-like domain required for the activation of the tyrosine kinase receptors of ErbB family. Four ErbB subtypes (ErbB1-4) have been identified, of which ErbB2, ErbB3 and ErbB4 mediate NRGs signaling, by constituting homo- and/or heterodimers upon NRGs binding, and activating different kinases pathways (Mei and Nave, 2014).

Several evidences support an important role for NRG1/ErbB signaling in the modulation of midbrain dopamine (DA) system. Actually, DA neurons express NRG1 and ErbB receptors, throughout development into adulthood (Steiner et al., 1999; Thuret et al., 2004; Abe et al., 2009; Namba et al., 2009; Zheng et al., 2009). Moreover, ErbB ligands have neurotrophic and neuroprotective effects on midbrain DA neurons. Thus, ErbB signaling activation fosters morphological/biochemical differentiation of immature DA cells (Casper et al., 1991; Ferrari et al., 1991;Casper and Blum, 1995; Farkas and Krieglstein, 2002; Zhang et al., 2004) and protects midbrain DA neurons from neurotoxin-induced degeneration either in neuronal cultures (Ostenfeld et al., 1999; Hanke et al., 2004; Zhang et al., 2004; Iwakura et al., 2005) or in mice models of Parkinson's diseases (PD) (Carlsson et al., 2011; Depboylu et al., 2015). Accordingly, the genetic deletion of ErbB receptors or their ligands impairs DA neuronal development (Erickson et al., 1997;Blum, 1998) and reveals behavioral anomalies usually associated with altered DA transmission (Stefansson et al., 2002; Futamura et al., 2003; Golub et al., 2004; Skirzewski et al., 2017).

NRG1/ErbB signaling affects DA neurotransmission, by acutely adjusting extracellular DA levels (Yurek et al., 2004;Kwon et al., 2008; Ledonne et al., 2015; Skirzewski et al., 2017). Indeed, intracerebral NRG1 injection either in the substantia nigra pars compacta (SNpc) (Yurek et al., 2004) or in the projection areas of nigrostriatal and mesolimbic/mesocortical pathways, like striatum (Skirzewski et al., 2017), hippocampus (Kwon et al., 2008) and medial prefrontal cortex (mPFC) (Skirzewski et al., 2017) increases extracellular DA levels. Moreover, endogenous ErbB signaling inhibition in SNpc precludes striatal DA release induced by glutamate-activated nigral depolarization (Ledonne et al., 2015). Furthermore, NRG1 exposure in neonatal period, due to sub-chronic systemic administration, prompts a persistent hyper-DAergic state in the PFC in the adulthood (Kato et al., 2010), and peripheral NRG1 administration in adult mice augments striatal DA levels (Carlsson et al., 2011). However, it has been also reported that adolescent rodents injected with a pan-ErbB inhibitor have increased striatal DA levels in the adulthood (Golani et al., 2014)

While the involvement of NRG1/ErbB receptors in the modulation of DA transmission appears evident, the underlying cellular/molecular mechanisms are less clear. Systemic neonatal NRG1 exposure has been associated to DA neurons hyperactivation (increased spike bursting and spontaneous firing), possible due to a reduced GABAergic transmission (Namba et al., 2016). Moreover, a functional interplay between ErbB4 and the DA transporter (DAT) in DAergic terminals has been proposed as an indirect mechanism by which NRG1/ErbB4 signaling regulates extracellular DA levels in the projecting areas (Skirzewski et al., 2017).

Regarding a direct role for NRG1/ErbB signaling in the regulation of the midbrain DA system, we have previously reported that it finely tunes glutamatergic transmission in DA neurons, by specifically affecting metabotropic glutamate receptors 1 (mGluR1) functioning (Ledonne et al., 2015). Indeed, NRG1/ErbB signaling controls new-synthesis and membrane trafficking of functional mGluR1 in SNpc DA neurons, thus affecting DA levels in the striatum (Ledonne et al., 2015).

mGluR1, together with mGluR5, belongs to the group 1 mGluRs (mGluRI) subclass of metabotropic glutamate receptors that are canonically linked to the $\mathrm{G}_{q / 11}$ heterotrimeric $\mathrm{G}$ proteins (Ferraguti et al., 2008). In SNpc DA neurons, mGluR1 and mGluR5 are both expressed, although higher levels have been reported for mGluR1 respect to mGluR5 (Testa et al., 1994; Hubert et al., 2001). Several functional evidences support a central role for mGluR1 in the modulation of midbrain DA system. Indeed, mGluR1 activation in SNpc DA neurons induces an inward current mediated by transient receptor potential channels (TRPC) (Guatteo et al., 1999; Tozzi et al., 2003; Ledonne et al., 2015), an outward current mediated by $\mathrm{Ca}^{2+}$-activated potassium channels $\left(\mathrm{K}_{\mathrm{Ca}}\right)$ (Fiorillo and Williams, 1998), as well as an increase in intracellular $\mathrm{Ca}^{2+}$ levels (Guatteo et al., 1999; Morikawa et al., 2003) and a facilitation of burst firing discharge (Prisco et al., 2002). Moreover, stimulation of nigral mGluR1 acutely increase DA release in the striatum of freely moving rats (Ledonne et al., 2015). Functional roles of mGluR5 in DA neurons are less characterized, although its activation contributes to DHPG-induced currents (Kramer and Williams, 2015; Ledonne et al., 2015).

It is largely accepted that mGluR $1 / 5$ are pivotal modulators of synaptic transmission, being involved in various forms of synaptic plasticity in several brain areas, including the hippocampus, dorsal and ventral striatum, mPFC and cerebellum (Collingridge et al., 2010; Lüscher and Huber, 2010). Regarding midbrain DA nuclei, a critical role for mGluR1 in the regulation of glutamatergic synaptic strength has been reported in DA neurons of the ventral tegmental area (VTA) (Bellone and Lüscher, 2006). The mGluR1-dependent long-term depression (LTD) in VTA is especially unmasked in synapses already potentiated by psychostimulants exposure (Mameli et al., 2007), thus being considered an endogenous mechanism to overcame excessive psychostimulants-induced plastic modifications of glutamatergic inputs to DA neurons (Lüscher and Huber, 2010).

Otherwise, the involvement of mGluR1 in long-term adjustment of excitatory synaptic strength in DA neurons of SNpc has been less characterized. Previous reports demonstrated that mGluRI activation depresses glutamatergic synaptic transmission in SNpc DAergic cells from rat midbrain slices (Bonci et al., 1997), but an analysis of potential long-term effects of mGluR1 activation on excitatory synaptic transmission is lacking.

To fill this gap in knowledge, we first aimed to characterize mGluRI-dependent long-term modifications of glutamatergic synaptic transmission in SNpc DA neurons, which has been induced by either chemical- or synaptic mGluRI activation. 
Then, in light of the evidence that NRG1/ErbB signaling is an endogenous regulator of mGluR1 function in SNpc DA neurons (Ledonne et al., 2015), and it modulates mGluRIdependent LTD in the hippocampus (Ledonne et al., 2018), we also tested the hypothesis that endogenous ErbB signaling, by controlling mGluRI-dependent functions, fine-tunes glutamatergic AMPAR-mediated synaptic strength in midbrain DA neurons.

\section{MATERIALS AND METHODS}

\section{Experimental Animals}

All procedures were carried out following the guidelines on the ethical use of animals from the Council Directive of the European Communities (2010/63/EU) and were approved by the Animal Care Committee of Santa Lucia Foundation (Authorization $\mathrm{N}^{\circ}$ DM81-2014 PR). C57BL6/J mice and Wistar rats were bred in our facility and housed in a temperature- $\left(23 \pm 1{ }^{\circ} \mathrm{C}\right)$ and humiditycontrolled environment ( $45 \%-60 \%$ relative humidity), with a $12 \mathrm{~h}$ light/dark cycle (lights off at 7 p.m.). Animals were allowed to take food and water ad libitum.

\section{Midbrain Slice Preparation}

Acute midbrain slices, used to perform electrophysiological experiments, were obtained following standard procedures, as described in Ledonne et al. (2012), with minor modifications.

Briefly, male C57BL6/J mice and Wistar rats (18-23 days old) were anesthetized with isoflurane and decapitated. The brain was rapidly removed from the skull and a tissue block containing the midbrain was isolated and immersed in cold artificial cerebrospinal fluid $(\mathrm{aCSF})$ at $8-10^{\circ} \mathrm{C}$. The aCSF contained (in $\mathrm{mM}$ ): $\mathrm{NaCl} 126, \mathrm{KCl} 2.5, \mathrm{MgCl}_{2} 1.2, \mathrm{CaCl}_{2} 2.4, \mathrm{NaH}_{2} \mathrm{PO}_{4}$ $1.2, \mathrm{NaHCO}_{3} 24$, glucose 10, saturated with $95 \% \mathrm{O}_{2}-5 \% \mathrm{CO}_{2}$ (pH 7.4). Horizontal slices (250 $\mu \mathrm{m}$ thick) of the ventral midbrain were cut using a vibratome (Leica VT1000S, Leica Microsystems, Wetzlar, Germany). Slices were maintained in aCSF at $33.0 \pm 0.5^{\circ} \mathrm{C}$ for $30 \mathrm{~min}$ before being transferred in the recording chamber for the electrophysiological recordings.

\section{Electrophysiology}

Whole-cell patch-clamp recordings of SNpc DA neurons were performed at $33.0 \pm 0.5^{\circ} \mathrm{C}$ in a recording chamber placed on the stage of an upright microscope (Axioscope FS, Zeiss, Gottingen, Germany), equipped for infrared video microscopy (Hamamatsu, Tokyo, Japan). Slices were continuously perfused at $2.5-3.0 \mathrm{ml} / \mathrm{min}$ with aCSF. SNpc neurons, visually selected by their localization and morphology, were identified as DAergic based on the presence of regular spontaneous firing at $1.5-3 \mathrm{~Hz}$ (in cell-attached mode). Patch-clamp recordings were performed with glass borosilicate pipettes (6-8 M $\Omega$ ) pulled with a PP-83 Narishige puller and filled with a solution

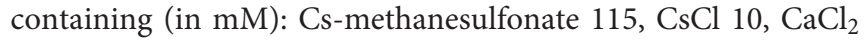
0.45, HEPES 10, EGTA 1, QX-314 5, MgATP 4, NaGTP 0.3 ( $\mathrm{pH} 7.3$ with $\mathrm{CsOH})$. A bipolar parallel stimulating electrode (FHC Inc., Bowdoin, ME, USA) was placed rostral to the DA neurons recorded (100-200 $\mu \mathrm{m})$. Excitatory postsynaptic currents (EPSCs) were evoked by delivering brief electrical pulses (100-200 $\mu$ s duration, every $30 \mathrm{~s})$ through a constantcurrent isolated stimulating unit (Digitimer, Welwey Garden City, UK). AMPAR-mediated EPSCs (AMPAR-EPSCs) were isolated by using the $\mathrm{GABA}_{\mathrm{A}}$ receptor antagonist, picrotoxin $(100 \mu \mathrm{M})$, the $\mathrm{GABA}_{\mathrm{B}}$ receptor antagonist, CGP55845 $(1 \mu \mathrm{M})$, the $\mathrm{D} 2$ receptor antagonist, sulpiride $(1 \mu \mathrm{M})$, and the NMDAR blocker, MK-801 (10 $\mu \mathrm{M})$. Amplitude and duration of stimulation pulses were set to obtain AMPAR-EPSCs of about 150-300 pA in baseline. A $2 \mathrm{mV}$ hyperpolarizing step was continuously applied before each AMPAR-EPSCs to monitor changes in access resistance $\left(\mathrm{R}_{\mathrm{a}}\right)$. Recordings were discarded if $\mathrm{R}_{\mathrm{a}}$ changed more than $>20 \%$ during experiments or holding currents (to $-70 \mathrm{mV}$ ) modified more than $100 \mathrm{pA}$ during recordings.

The low frequency stimulation (LFS) protocol consisted in the delivery of pulses at the frequency of $1 \mathrm{~Hz}$ for $10 \mathrm{~min}$ (600 pulses), being the pulse amplitude and duration the same used for evoked AMPAR-EPSCs.

Otherwise stated, drugs were bath applied at known concentrations via a three-way tap system. A complete exchange of the solution in the recording chamber occurred in about 1 min. In a set of experiments, the pan-ErbB inhibitor PD158780 or the ErbB2 inhibitor, CP724714, as well as their vehicle (dimethyl sulfoxide, DMSO) were intracellular applied in SNpc DA neurons through the patch-clamp pipettes, during electrophysiological recordings. Thus, PD158780 and CP-724714 were dissolved at the final concentration of $1 \mu \mathrm{M}$ in the pipette filling solution (1:10,000 in DMSO).

In another set of experiments, to investigate NRG1's effect on mGluRI-dependent LTD, midbrain slices were kept in a holding chamber containing standard aCSF, saturated with $95 \%$ $\mathrm{O}_{2}-5 \% \mathrm{CO}_{2}$ at $33.0 \pm 0.5^{\circ} \mathrm{C}$, in presence of picrotoxin $(100 \mu \mathrm{M})$, MK-801 (10 $\mu \mathrm{M})$, CGP55845 $(1 \mu \mathrm{M})$ and sulpiride $(1 \mu \mathrm{M})$ (CTR), with the addition of NRG1 (5 nM, $30 \mathrm{~min}$ ) or PD158780 + NRG1 (NRG1 $5 \mathrm{nM}$ plus PD158780 $10 \mu \mathrm{M}$ for 30 min preceded by PD158780 $10 \mu \mathrm{M}, 10 \mathrm{~min}$ ), and then transferred in the recording chamber. Electrophysiological recordings on treated slices started within $30 \mathrm{~min}$ after the end of the treatment (slice removal from incubation chamber). Drug concentrations and durations of treatments were designed according to previous evidence (Ledonne et al., 2015, 2018).

AMPAR-EPSCs were analyzed by measuring peak amplitude and data were normalized to baseline. LTD magnitude was calculated by averaging AMPAR-EPSCs amplitude during last 5 min of recordings (i.e., 25-30 min after DHPG application).

\section{Statistical Analyses}

Numerical data were expressed as mean \pm SEM. Statistical comparisons of LTD magnitude were performed using Student's unpaired $t$-test or One-way ANOVA, as appropriate.

\section{Drugs}

Recombinant human NRG1 $\beta 1$ (EGF-like domain), sulpiride and isoflurane were purchased from Sigma-Aldrich (Milano, IT). PD158780 and CGP55845 were obtained from Tocris (Bristol, UK). (S)-DHPG, CP-724714, MK-801, 
Picrotoxin, CNQX, CPCCOEt and MPEP were from Abcam (Cambridge, UK).

\section{RESULTS}

\section{mGluR1-Dependent LTD of Glutamatergic Synaptic Transmission in SNpc DA Neurons}

To characterize the functional role of mGluRI in the regulation of excitatory synaptic plasticity in SNpc DA neurons, we performed patch-clamp recordings from these cells in midbrain slices of C57BL6 mice by analyzing the effect of an acute mGluRI stimulation, by means of the mGluRI agonist (S)-DHPG, on glutamatergic AMPARs-mediated synaptic transmission. We found that bath application of (S)-DHPG (100 $\mu \mathrm{M}, 10 \mathrm{~min})$ induces an LTD of AMPAR-mediated excitatory postsynaptic currents (AMPAR-EPSCs) in SNpc DA neurons, being AMPAREPSCs mean amplitude reduced to $73.40 \pm 0.48 \%$ of baseline ( $n=13$ cells $/ 9$ mice), at $25-30 \mathrm{~min}$ after DHPG exposure (Figures 1A,B,E).

To verify the selective involvement of mGluR1, rather than mGluR5, in DHPG-induced LTD, we analyzed LTD magnitude in midbrain slices treated with the selective mGluR1 antagonist, CPCCOEt or the mGluR5 antagonist, MPEP, respectively. Notably, DHPG-induced LTD was prevented by a pre-treatment with CPCCOEt, being not affected by MPEP (Figures 1A,C,D). Indeed, in slices treated with CPCCOEt $(50 \mu \mathrm{M})$ for $20 \mathrm{~min}$ before and during DHPG application AMPAR-EPSCs mean amplitude was $111.00 \pm 2.79 \%$ of baseline $(n=7$ cells $/ 4$ mice, $p<0.001$; Figure 1E) whereas in slices treated with MPEP $(10 \mu \mathrm{M})$ for $20 \mathrm{~min}$ before and during DHPG AMPAREPSCs amplitudes were reduced to $79.77 \pm 1.27 \%$ of baseline ( $n=5$ cells $/ 4$ mice, $p>0.05$; Figure 1E).

The application of a prolonged low frequency electrical stimulation (LFS) determines a mGluRI-dependent LTD of glutamatergic synaptic transmission in different brain areas, as a consequence of extrasynaptic mGluR1/5 activation, by means of endogenous glutamate spillover (Bellone and Lüscher, 2006;Volk et al., 2006). To verify whether LFS could induce, by mGluR1, an LTD in SNpc DA neurons, we analyzed AMPAR-EPSCs amplitude while applying a classical LFS protocol (1 Hz, 600 pulses). We found that LFS delivery produced an LTD of AMPAR-mediated synaptic transmission in SNpc DA neurons (Figures 1F,G), reducing AMPAR-EPSCs mean amplitude to $68.81 \pm 1.56 \%$ of baseline ( $n=8$ cells/5 mice; Figure 1J). LFS-induced LTD was reliant on selective mGluR1 activation, since it was counteracted by a pre-treatment with the mGluR1 antagonist CPCCOEt (Figures 1F,H), but not influenced by the mGluR5 antagonist MPEP (Figures 1F,I). Actually, following LFS delivery AMPAREPSCs mean amplitude was reduced to $88.49 \pm 1.28 \%$ of baseline in SNpc DA neurons from slices treated with CPCCOEt $(50 \mu \mathrm{M})$ for $20 \mathrm{~min}$ before and during LFS $(n=6$ cells $/ 4$ mice, $p<0.001$, unpaired $t$-test; Figure 1J) while its amplitude was $72.53 \pm 2.11 \%$ of baseline in DA cells from slices treated with MPEP $(10 \mu \mathrm{M})$ for $20 \mathrm{~min}$
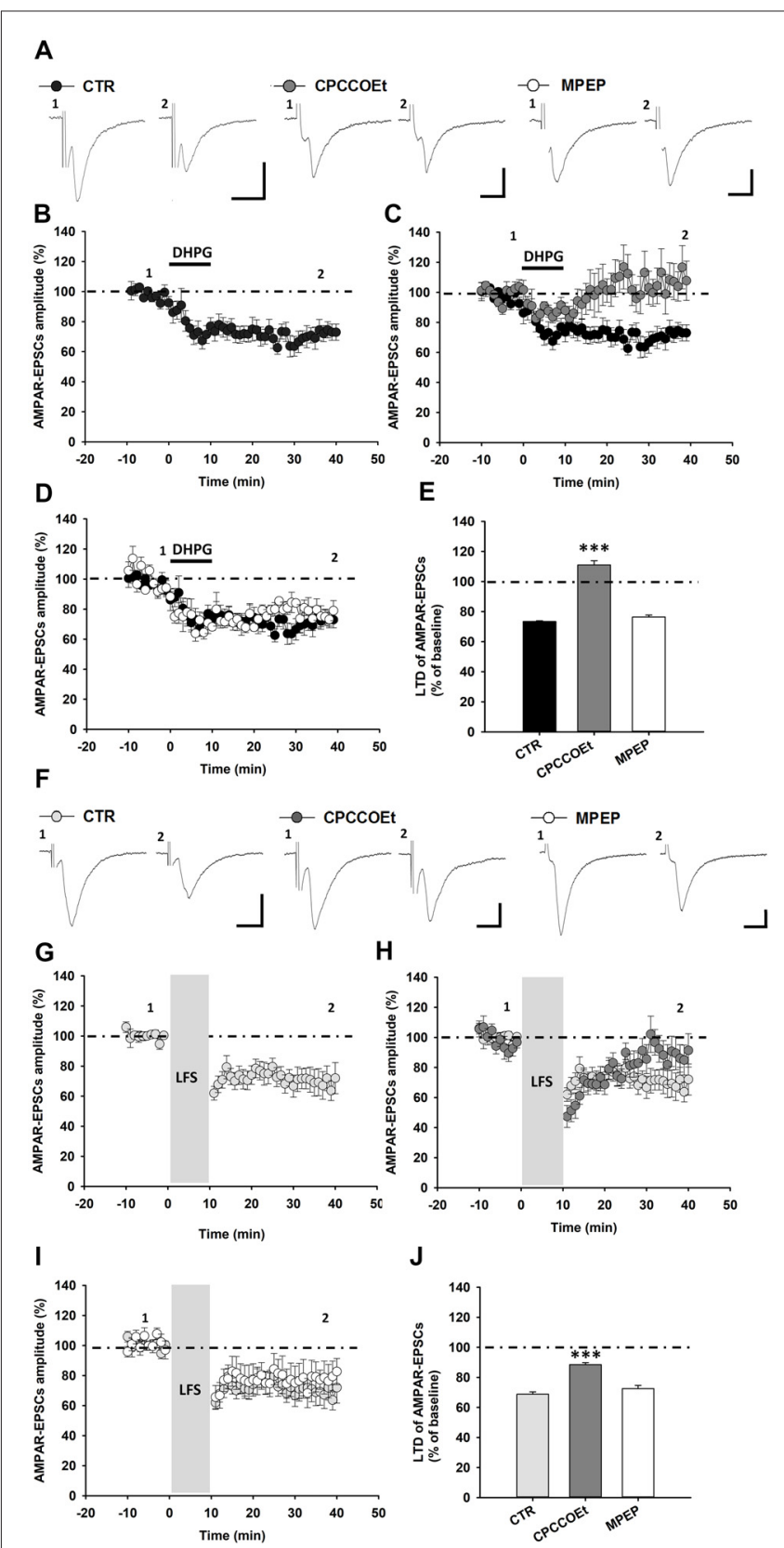

FIGURE 1 | Metabotropic glutamate receptors 1 (mGluR1)-dependent long-term depression (LTD) in substantia nigra pars compacta (SNpc) dopamine (DA) neurons. (A-E) mGluRl activation with DHPG (100 $\mu \mathrm{M}$, $10 \mathrm{~min}$ ) induces an LTD of AMPAR-mediated excitatory postsynaptic currents (AMPAR-EPSCs) in SNpc DA neurons, which is dependent on the selective activation of mGluR1, but not mGluR5 receptors. (A) Representative traces of AMPAR-EPSCs showing the effect of DHPG (100 $\mu \mathrm{M}, 10 \mathrm{~min})$ in control condition and in the presence of the mGluR1 antagonist, CPCCOEt (50 $\mu \mathrm{M})$ or the mGluR5 antagonist, MPEP (10 $\mu \mathrm{M})$ before (1) and after (2) DHPG application. The synaptic depression of DHPG-induced LTD (B) is counteracted by a pretreatment with CPCCOEt (C) but not MPEP (D), as reported in the histogram (E) showing the magnitude of DHPG-induced LTD of AMPAR-EPSCs in the different pharmacological conditions. DHPG-induced LTD: CTR ( $n=13$ cells $/ 9$ mice), CPCCOEt $(n=7$ cells $/ 4$ mice), MPEP ( $n=$ 5 cells $/ 4$ mice), ${ }^{* * *} p<0.001$ CPCCOEt vs. CTR, One-way ANOVA followed by Tukey's test. (F-J) mGluR1 activation, by means

(Continued) 
FIGURE 1 | Continued

of synaptically-induced glutamate release with a low frequency electrical stimulation (LFS), causes an LTD of AMPAR-EPSCs in SNpc DA neurons. (F) Representative traces showing AMPAR-EPSCs before (1) and after (2) the delivery of a protocol of LFS (1 Hz, $10 \mathrm{~min}$ ) in control condition and in the presence of the mGluR1 antagonist, CPCCOEt or the mGluR5 antagonist, MPEP. (G) LFS-induced LTD is antagonized by a treatment with CPCCOEt (50 $\mu \mathrm{M}, 20$ min before and during LFS) (H) but not MPEP $(10 \mu \mathrm{M}, 20 \mathrm{~min}$ before and during LFS) (I), as showed in the histogram (J) reporting the magnitude of LFS-induced LTD in the different pharmacological conditions. LFS-induced LTD: CTR ( $n=8$ cells $/ 5$ mice), CPCCOEt ( $n=6$ cells $/ 4$ mice), MPEP ( $n=7$ cells $/ 5$ mice), ${ }^{* * *} p<0.001$ CPCCOEt vs. CTR, One-way ANOVA followed by Tukey's test. (A,F) Scale bar: 100 pA, 5 ms.

before and during LFS protocol $(n=7$ cells $/ 5$ mice; $p>0.05$; Figure 1J).

Altogether, these results support a major role for mGluR1, rather than mGluR5, in the modulation of synaptic strength in SNpc DA neurons, being mGluR1 critically involved in either pharmacological or synaptic forms of LTD of AMPAR-mediated synaptic transmission.

\section{Endogenous ErbB Signaling-Dependent Regulation of mGluR1-Induced LTD in DA Neurons}

To investigate whether NRG1/ErbB signaling affects mGluR1dependent synaptic plasticity in SNpc DA neurons, we analyzed DHPG-induced LTD in control condition and after NRG1/ErbB signaling modulation. First, we aimed to determine the role of endogenous NRG1/ErbB tone, by evaluating the effect of a treatment with the broad spectrum ErbB inhibitor, PD158780, on DHPG-induced LTD. We found that a pre-treatment with PD158780 $(10 \mu \mathrm{M}), 20 \mathrm{~min}$ before and during DHPG application significantly blunted DHPG-induced LTD (Figures $\mathbf{2 A - C}$ ). Indeed, in SNpc DA neurons from PD158780-treated slices, AMPAR-EPSCs mean amplitude, at 25-30 min after DHPG application, was $89.05 \pm 1$. $29 \%$ of baseline $(n=7$ cells $/ 6$ mice, $p<0.001)$. PD158780 per se did not modified basal AMPAR-mediated transmission.

To further confirm the contribution of ErbB receptors in controlling mGluR1-dependent synaptic plasticity in SNpc DA neurons, we assessed the effect of PD158780 on LFS-induced LTD. Notably, PD158780 (10 $\mu \mathrm{M})$, applied $25 \mathrm{~min}$ before and during LFS, similarly counteracted LTD of AMPAR-mediated synaptic transmission (Figures 2D-F), since AMPAR-EPSCs amplitude in SNpc DA neurons recorded from PD158780treated slices was $89.44 \pm 2.85 \%(n=7$ cells $/ 5$ mice, $p<0.001)$.

Next, we aimed to verify whether this ErbB-dependent modulation of mGluR1-activated LTD is a species conserved mechanism of regulation of glutamatergic synaptic strength in SNpc DA neurons. Thus, we analyzed the contribution of ErbB receptors in mGluR1-dependent LTD in midbrain slices from Wistar rats. As in C57BL6/J mice, the pharmacological activation of mGluRI, by DHPG, in rat midbrain slices, caused a robust reduction of AMPAR-EPSCs in DA neurons, with AMPAR-EPSCs amplitude being diminished to $52.73 \pm 1.30 \%$ of baseline ( $n=8$ cells $/ 6$ rats; Figures $3 \mathbf{A}, \mathbf{B}, \mathbf{E})$. We found that also in Wistar rats DHPG-induced LTD was reliant on the selective activation of mGluR1, being antagonized by a pretreatment with the mGluR1 antagonist, CPCCOEt (Figures 3A,C,E), but not affected by the mGluR5 antagonist, MPEP (Figures 3A,D,E). Indeed, AMPAR-EPSCs mean amplitude in CPCCOEt-treated slices was $96.32 \pm 2.35 \%$ of baseline ( $n=5$ cells $/ 5$ rats) whereas in MPEP-treated slices was $58.81 \pm 0.89 \%$ of baseline $(n=5$ cells $/ 5$ rats; $p<0.001$ CTR vs CPCCOEt).

Notably, the inhibition of endogenous ErbB signaling, with PD158780, antagonized DHPG-induced LTD also in SNpc DA neurons of rats. Indeed, in rat midbrain slices treated with PD158780 (10 $\mu \mathrm{M}, 20$ min before and during DHPG application) the mean amplitude of AMPAR-EPSCs was $86.52 \pm 0.97 \%$ ( $n=8$ cells $/ 6$ rats, $p<0.001$; Figures $3 \mathbf{F}-\mathbf{H})$.

Then, we evaluated whether a synaptically-induced mGluR1dependent LTD could be similarly elicited, with an LFS protocol, in rat SNpc DA neurons, being also reliant on ErbB receptors activation. Likewise, the delivery of an LFS protocol $(1 \mathrm{~Hz}$, 600 pulses) to rat midbrain slices induced an mGluR1-dependent LTD of AMPAR-mediated synaptic transmission in DA neurons (Figures 4A,B), causing a reduction of AMPAR-EPSCs mean amplitude to $56.66 \pm 0.38 \%$ of baseline $(n=7$ cells $/ 5$ rats; Figure 4E). Indeed, this LFS-induced LTD was completely blunted in the presence of CPCCOEt $(100 \mu \mathrm{M})$, applied for $20 \mathrm{~min}$ before and during LFS (AMPAR-EPSCs mean amplitude $104.42109 .40 \pm 1.36 \%$ of baseline, $n=9$ cells $/ 7$ rats, $p<0.001$, CTR vs. CPCCOEt; Figures 4A,C,E), but was not influenced by a pretreatment with MPEP $(10 \mu \mathrm{M})$, applied $20 \mathrm{~min}$ before and during LFS (AMPAR-EPSCS mean amplitude $58.60 \pm 0.86 \%$ of baseline, $n=5$ cells $/ 4$ rats; Figures 4A,D,E), thus confirming herein, as in C57BL6/J mice, a prominent contribution of mGluR1 subtypes in this form of synaptic plasticity. Notably, a pretreatment with the pan-ErbB inhibitor PD158780 completely antagonized LFS-induced LTD and unmasked a potentiation of AMPAR-mediated synaptic transmission, following LFS delivery (Figures 4F-H). Indeed, AMPAR-EPSCs mean amplitude in PD158780-treated slices was $121.20 \pm 1.57 \%$ of baseline $(n=5$ cells $/ 5$ rats; $p<0.001$; CTR vs. PD158780; Figure 4H).

Altogether, these results point to a conserved endogenous ErbB signaling-dependent mechanism of regulation of mGluR1dependent LTD in SNpc DA neurons in the two different rodent species.

\section{Subunit Composition of ErbB Receptors Modulating mGluR1-Dependent LTD in DA Neurons}

We previously reported that ErbB receptors containing ErbB2 and ErbB4 subunits are involved in NRG1-dependent regulation of mGluR1 functioning in rat SNpc DA neurons (Ledonne et al., 2015). To verify the contribution of these specific ErbB subunits in the modulation of mGluR1-dependent LTD in C57BL6/J mice, we applied ErbB inhibitors inside DA neurons through the patch-clamp pipettes, then recording DHPG-induced LTD. Indeed, we analyzed modifications in 
A

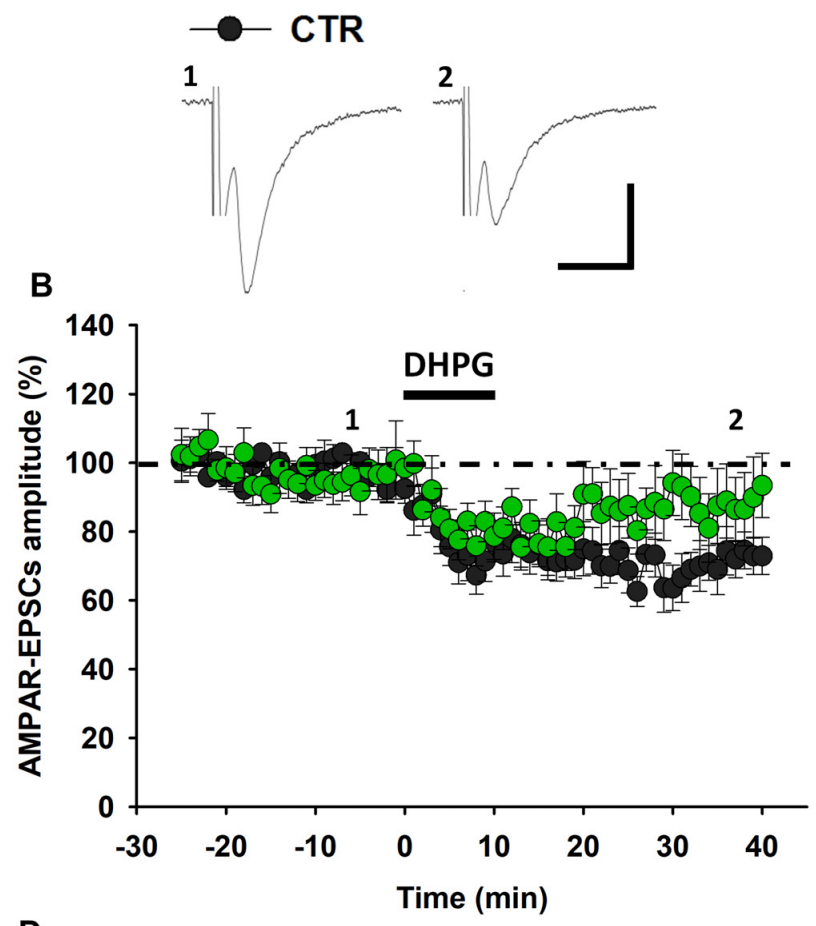

D
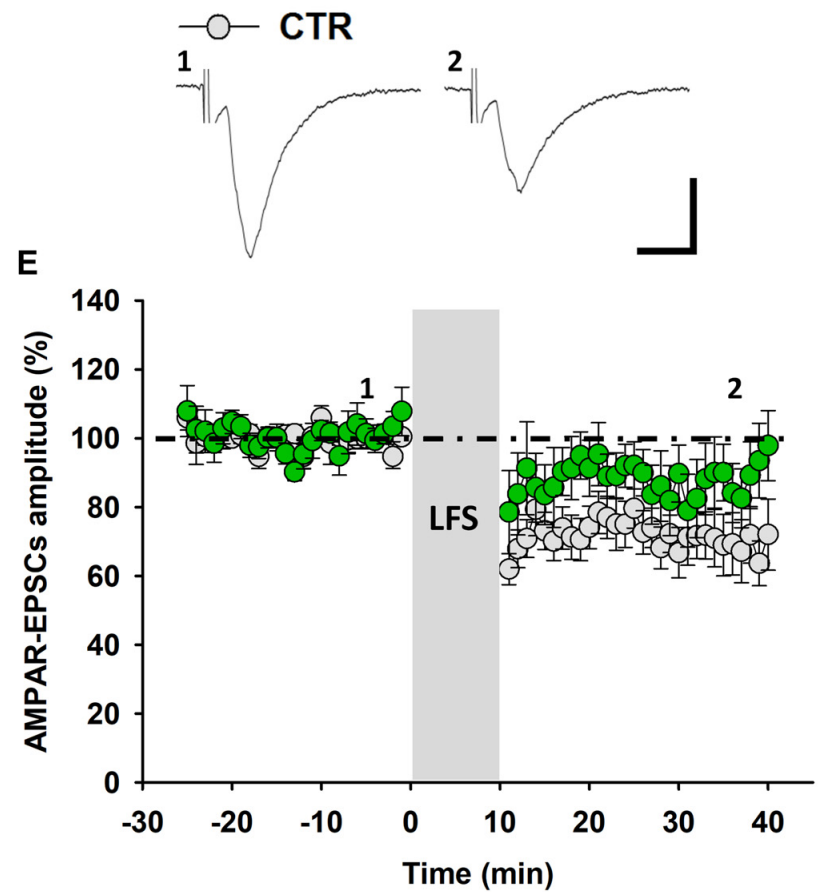
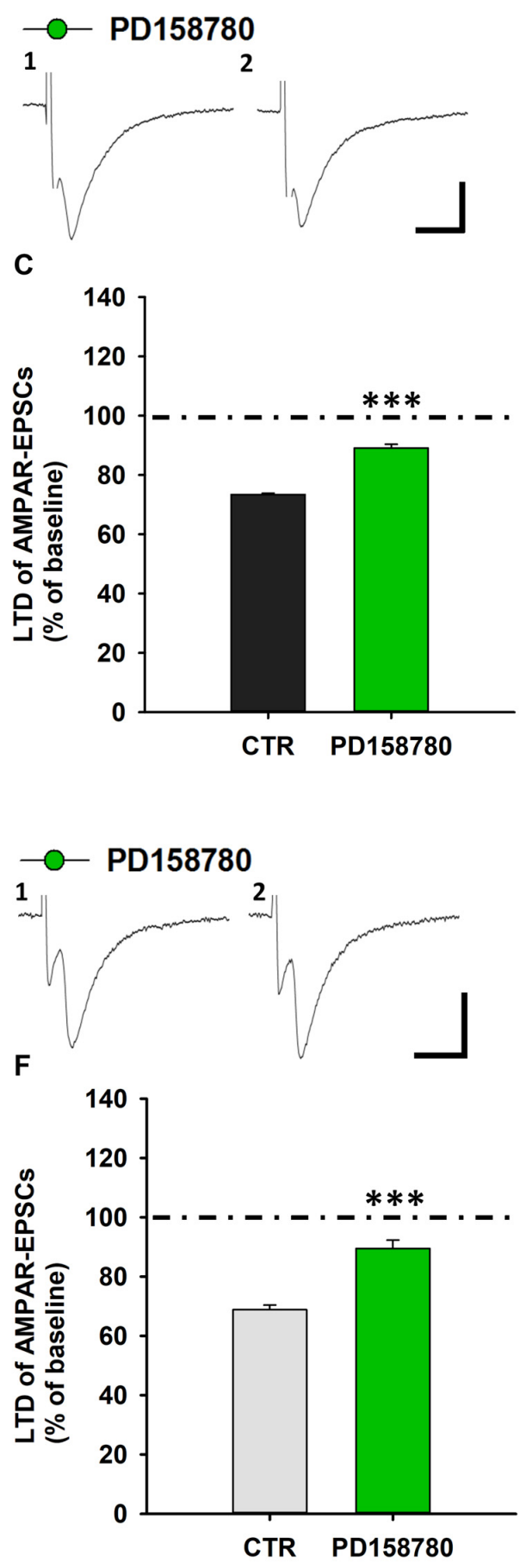

FIGURE 2 | ErbB signaling inhibition counteracts mGluR1-dependent LTD in SNpc DA neurons from C57BL6 mice. (A-C) DHPG-induced LTD is antagonized by a treatment with the broad spectrum ErbB inhibitor PD158780. (A) Representative traces showing AMPAR-EPSCs before (1) and after (2) DHPG application in control conditions and in the presence of the pan-ErbB inhibitor, PD158780. (B) Time course of DHPG-induced LTD of AMPAR-EPSCs in control- and PD158780-treated slices. (C) Plot showing that the magnitude of DHPG-induced LTD is significantly reduced by a pretreatment with PD158780 (10 $\mu$ M, 20 min before and during DHPG application). CTR ( $n=13$ cells/9 mice) and PD158780 ( $n=7$ cells/6 mice), ${ }^{* * *} p<0.001$. (D-F) LFS-induced LTD is counteracted by PD158780, as showed in the representative traces of AMPAR-EPSCs before (1) and after (2) the delivery of an LFS protocol (1 Hz, $10 \mathrm{~min}$; D) and plots of time course (E) and magnitude (F) of LFS-induced LTD in control conditions and in slices treated with PD158780 (10 $\mu \mathrm{M}, 20 \mathrm{~min}$ before and during LFS delivery). CTR $(n=8$ cells/5 mice) and PD158780 ( $n=7$ cells/5 mice), $\left.{ }^{* *} p<0.001\right)$. (A,D) Scale bar: 100 pA, 5 ms. 
A

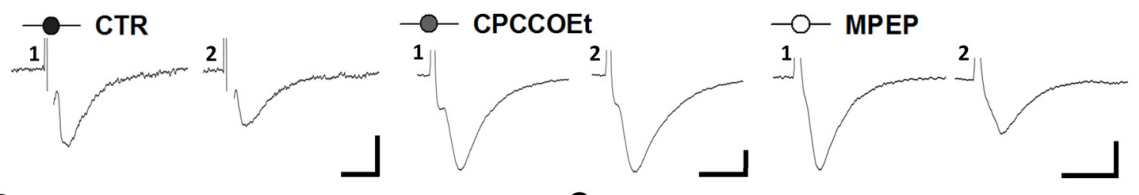

B

C
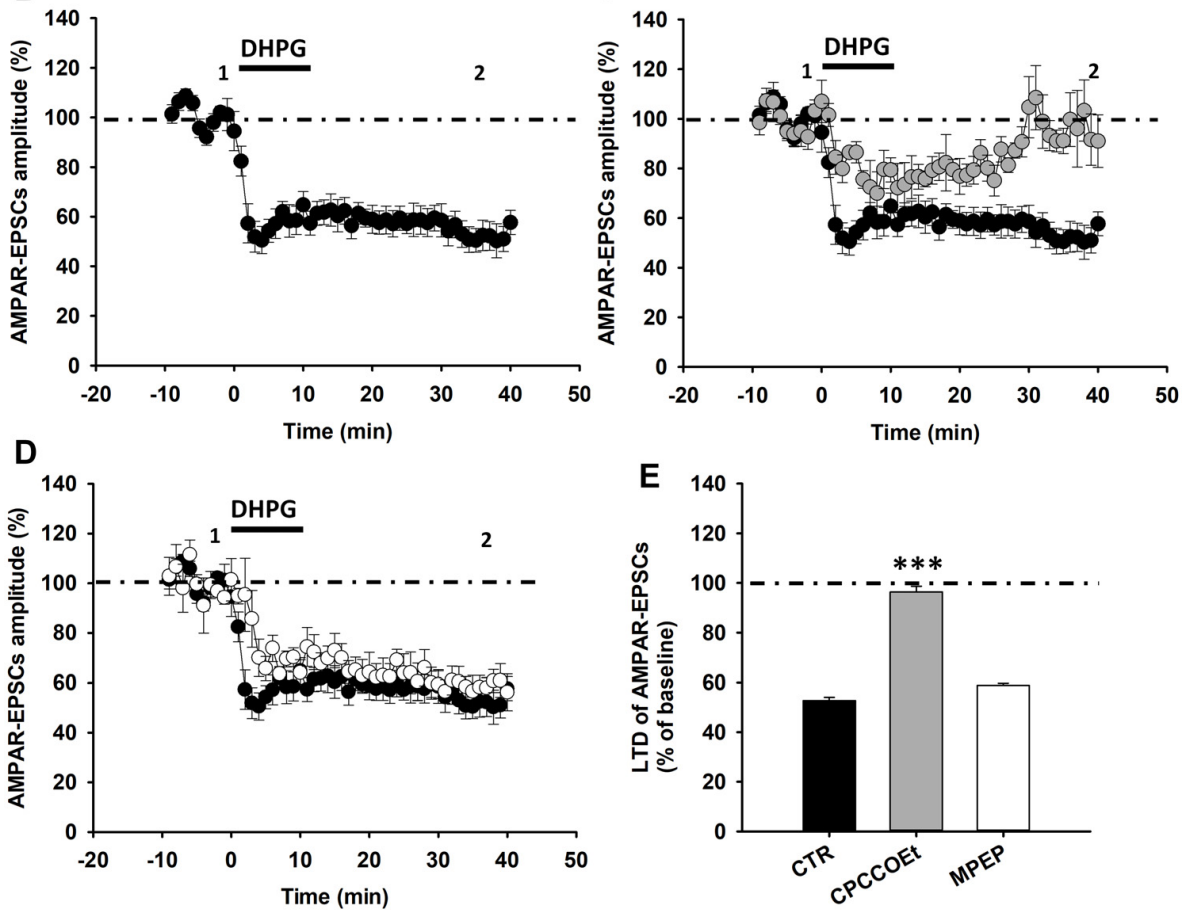

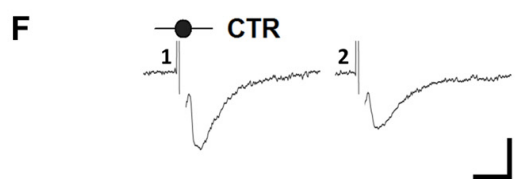

G

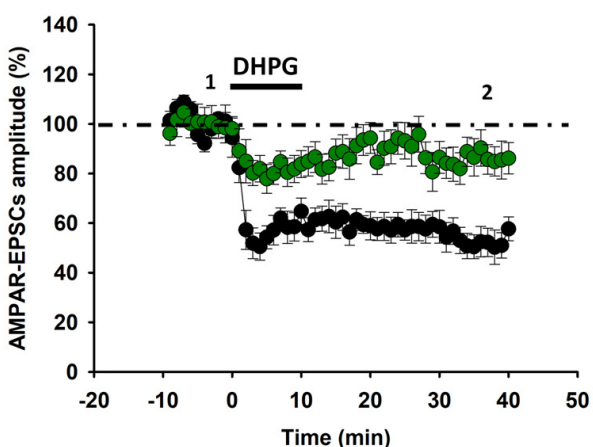

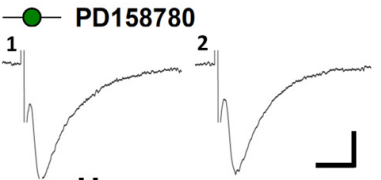

H

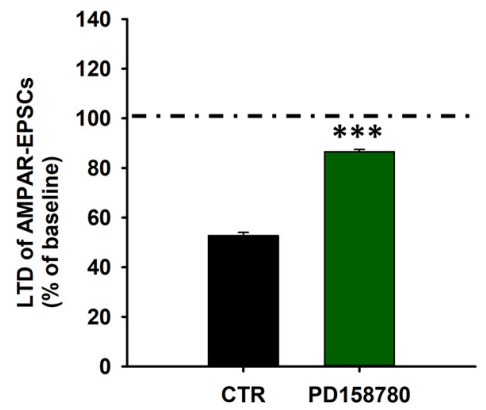

FIGURE 3 | ErbB signaling inhibition affects mGluR1-dependent LTD in SNpc DA neurons from Wistar rats. (A-E) DHPG-induced LTD in SNpc DA neurons from Wistar rats. (A) Examples of AMPAR-EPSCs before (1) and after (2) the application of DHPG (100 $\mu \mathrm{M}, 10 \mathrm{~min})$ in control condition and in slices treated with CPCCOEt $(100 \mu \mathrm{M})$ or MPEP $(10 \mu \mathrm{M})$. DHPG-induced LTD (B) is antagonized by a pretreatment with CPCCOEt (C), while is not affected by MPEP (D), as reported in the histogram (E) showing magnitudes of DHPG-induced LTD of AMPAR-EPSCs in the different pharmacological conditions. CTR ( $n=8$ cells/ 6 rats), CPCCOEt ( $n=5$ cells $/ 5$ rats), MPEP ( $n=5$ cells $/ 5$ rats). ${ }^{* * *} p<0.001$ CPCCOEt vs. CTR, One-way ANOVA followed by Tukey's test. (F-H) DHPG-induced LTD is reliant on endogenous ErbB signaling activation in midbrain slices from Wistar rats. (F) Examples of AMPAR-EPSCs before (1) and after (2) the application of DHPG (100 $\mu$ M, $10 \mathrm{~min}$ ) in control condition and in slices treated with PD158780 (10 $\mu \mathrm{M}, 20$ min before and during DHPG). (G,H) Plots of time course (G) and magnitude (H) of DHPG-induced LTD in different pharmacological conditions. CTR ( $n=8$ cells/6 rats) and PD158780 ( $n=8$ cells/6 rats), ${ }^{* * *} p<0.001$. (A,F) Scale bar: 100 pA, 5 ms. 
A

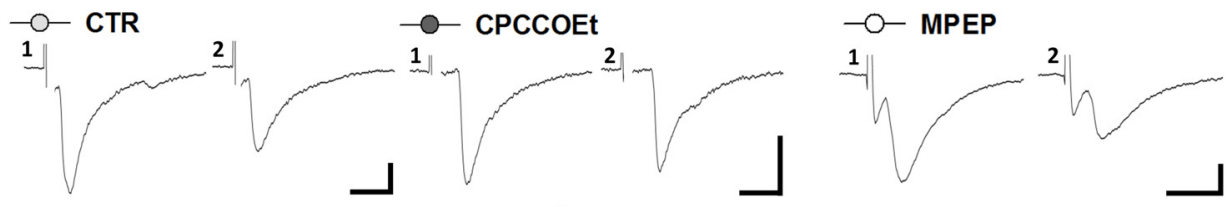

B

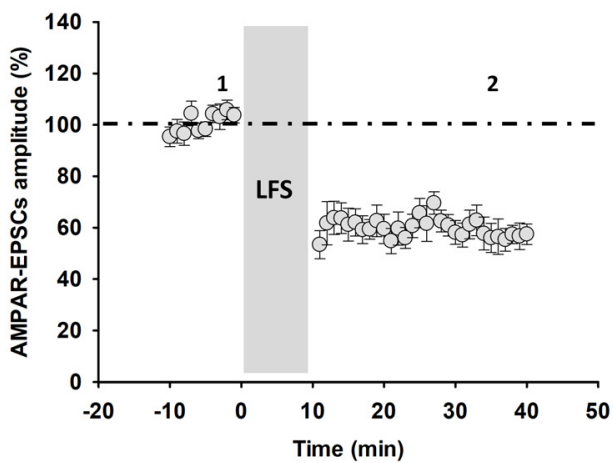

D

C

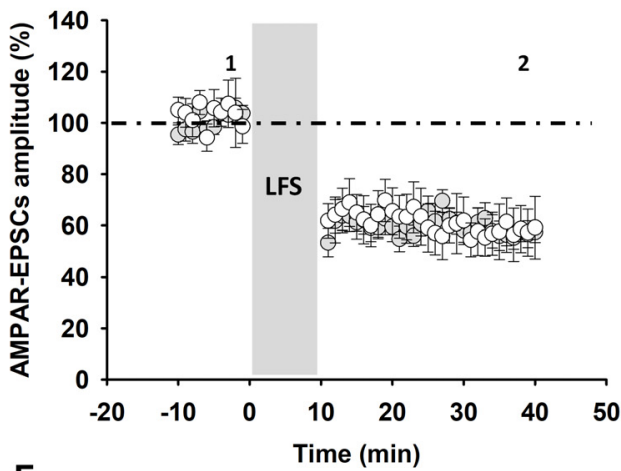

E
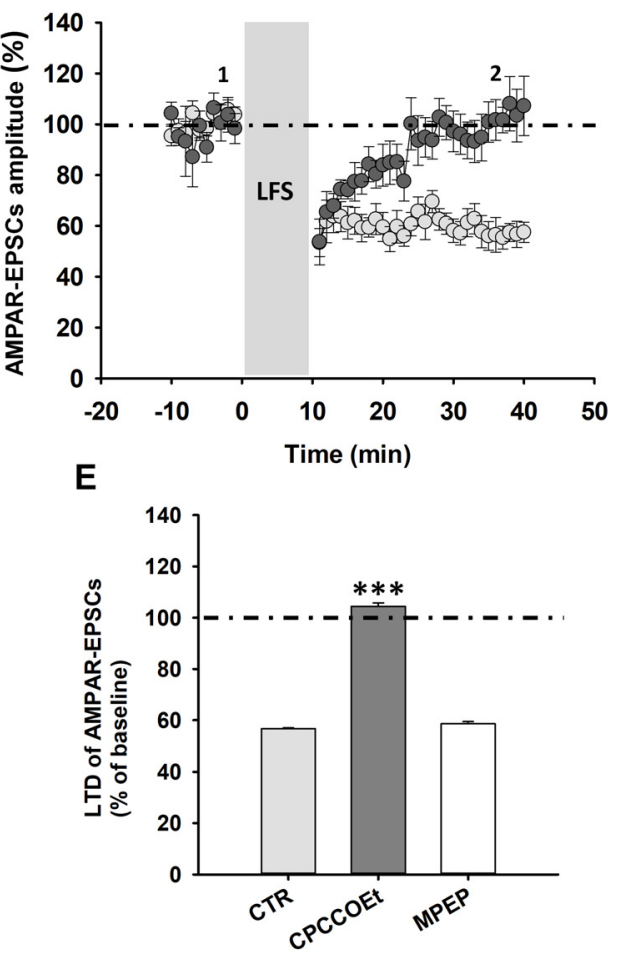

$\mathbf{F}$

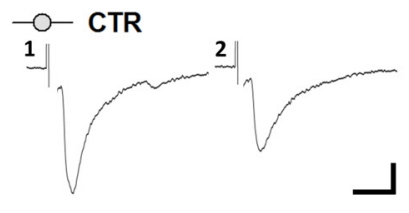

G
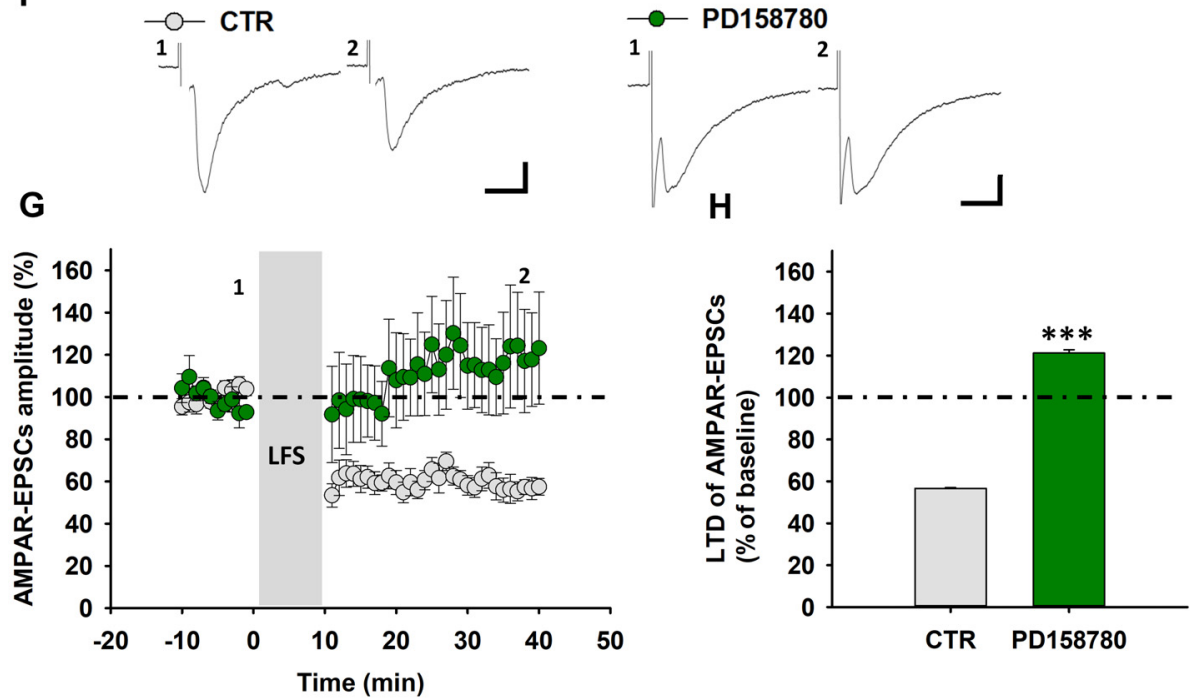

FIGURE 4 | LFS-induced LTD in SNpc DA neurons from Wistar rats is affected by ErbB signaling inhibition. (A) Representative traces of AMPAR-EPSCs before (1) and after (2) the delivery of LFS (1 Hz, $10 \mathrm{~min})$ in control conditions and in slices treated with the mGluR1 antagonist, CPCCOEt (100 $\mu \mathrm{M}, 20 \mathrm{~min}$ before and during LFS) or the mGluR5 antagonist MPEP (10 $\mu \mathrm{M}, 20$ min before and during LFS). LFS delivery in midbrain slices from Wistar rats induces an LTD (B) which is dependent on the selective mGluR1 activation, since is counteracted by a pretreatment with CPCCOEt (C) but not MPEP (D), as reported in the histogram (E) showing magnitudes of LFS-induced LTD in control conditions and in slices treated with CPCCOEt or MPEP. CTR ( $n=7$ cells $/ 5$ rats), CPCCOEt $(n=9$ cells $/ 7$ rats), 
FIGURE 4 | Continued

$\operatorname{MPEP}\left(n=5\right.$ cells $/ 4$ rats). ${ }^{* * *} p<0.001$ CTR vs. CPCCOEt, One-way ANOVA followed by Tukey's test. (F-H) LFS-induced LTD is prevented by the ErbB inhibitor PD158780, as showed in the representative traces of AMPAR-EPSCs (F) before (1) and after (2) the delivery of an LFS protocol (1 Hz, $10 \mathrm{~min}$ ) and plots of time course (G) and magnitude (H) of LFS-induced LTD in control conditions and in slices treated with PD158780 (10 $\mu \mathrm{M}, 20$ min before and during LFS delivery). CTR ( $n=7$ cells/5 rats) and PD158780 ( $n=5$ cells $/ 5$ rats), ${ }^{* * *} p<0.001$. (A,F) Scale bar: 100 pA, 5 ms.

LTD magnitude in DA neurons injected with a broad spectrum ErbB inhibitor, PD158780, which inhibits either ErbB2 and ErbB4 subunits as well as the effects of the intracellular injection of a selective ErbB2 inhibitor, CP-724714.

We found that the intracellular application of PD158780 (1 $\mu \mathrm{M}$ ) diminished mGluR1-dependent LTD. Indeed, the magnitude of LTD induced by DHPG (100 $\mu \mathrm{M}, 10 \mathrm{~min})$ in PD158780-injected cells was significantly reduced respect to vehicle-injected cells (0.0001\% DMSO; Figures 5A-C), being AMPAR-EPSCs mean amplitude $70.73 \pm 1.18 \%$ of baseline in vehicle-injected cells ( $n=5$ cells $/ 4$ mice) and $83.31 \pm 0.98 \%$ in PD158780-injected cells $(n=8$ cells $/ 6$ mice, $p<0.001$, Vehicle vs. PD158780). Similarly, LTD magnitude was significantly blunted in SNpc DA neurons injected with the ErbB2 inhibitor CP-724714, respect to vehicle-injected neurons (Figures 5D-F), being AMPAR-EPSCs mean amplitude in CP-724714-injected cells $91.26 \pm 2.77 \%$ of baseline $(n=7$ cells $/ 6$ mice, $p<0.001$ vehicle vs. CP-724714).

These results support a key functional role of ErbB receptors, possible as ErbB2-ErbB4 dimers, specifically localized in SNpc DA neurons in the modulation of excitatory synaptic transmission in these neuronal population, by means of a specific regulation of mGluR1-dependent LTD.

\section{Exogenous NRG1 Increases mGluR1-Dependent Synaptic Depression in DA Neurons}

Then, we investigated whether exogenous NRG1 could affect mGluR1-dependent synaptic plasticity in SNpc DA neurons of C57BL6 mice. To this end we compared the magnitude of DHPG-induced LTD in midbrain slices treated with NRG1 (5 $\mathrm{nM}, 30 \mathrm{~min}$ ) respect to control slices. We found that in NRG1-treated slices DHPG-induced LTD is marginally increased (Figures 6A-C), since AMPAR-EPSCs mean amplitude, following application of DHPG (100 $\mu \mathrm{M}, 10 \mathrm{~min})$ was reduced to $65.57 \pm 1.46 \%$ of baseline in NRG1-treated slices ( $n=6$ cells $/ 5$ mice) and to $71.98 \pm 1.68 \%$ in control (CTR) slices ( $n=5$ cells $/ 5$ mice, $p<0.05$, CTR vs. NRG1).

To possible unmask a more pronounced potentiating effect of NRG1 on mGluR1-dependent synaptic plasticity, we investigate the effect of NRG1 in condition of minimal mGluRI activation, which cause a minor synaptic depression in control conditions. We found that in NRG1-treated slices the synaptic depression induced by DHPG $(10 \mu \mathrm{M}, 10 \mathrm{~min})$ is considerably potentiated (Figures 6D-F). Indeed DHPG $(10 \mu \mathrm{M})$ reduced AMPAR-EPSCs mean amplitude to $89.44 \pm 1.69 \%$ of baseline
( $n=9$ cells $/ 7$ mice) in CTR slices and to $74.22 \pm 0.77 \%$ of baseline in NRG1-treated slices $(n=9$ cells/8 mice; $p<0.001$, CTR vs. NRG1). This NRG1-dependent potentiation of DHPG-induced LTD is mediated by the activation of ErbB receptors, since it was prevented by the pan-ErbB inhibitor PD158780. Indeed, in slices treated with PD158780 $(10 \mu \mathrm{M})$ for $10 \mathrm{~min}$ before and during the incubation with NRG1 (5 nM, $30 \mathrm{~min}$ ) AMPAR-EPSCs amplitudes, following DHPG application, were $91.21 \pm 1.16 \%$ of baseline $(n=6$ cells $/ 5$ mice, $p<0.001$, NRG1 vs. PD158780 + NRG1; Figures 6D-F).

Overall, these results support an important role for NRG1-induced ErbB signaling activation in adjusting mGluR1dependent LTD in midbrain DA neurons.

\section{DISCUSSION}

Here, we describe a novel form of mGluR1-dependent long-term synaptic plasticity in SNpc DA neurons in two different rodent species (mice and rats), and demonstrate that it is controlled by NRG1/ErbB signaling activation. In particular, we reported that either pharmacological or synaptic stimulation of mGluR1 causes an LTD of AMPAR-mediated synaptic transmission in SNpc DA neurons, which is reliant on endogenous ErbB activation tone within DA neurons. Thus, we disclose a new role for NRG1/ErbB signaling in the regulation of glutamatergic synaptic transmission in midbrain DA neurons.

Several evidences demonstrate that NRG1/ErbB signaling controls glutamatergic transmission in different brain areas, by means of various mechanisms which are area- and synapsesspecific, being also related to the activation state of synapses. There is a general consensus that NRG1/ErbB signaling does not affect basal ionotropic glutamatergic transmission, since it does not modify AMPAR- or NMDAR-induced currents in hippocampal CA1 pyramidal neurons (Huang et al., 2000; Kwon et al., 2005; Bjarnadottir et al., 2007; Iyengar and Mott, 2008; Chen et al., 2010; Ledonne et al., 2018) as well as in cultured cerebellar granule neurons (Fenster et al., 2012) and in midbrain DA cells (Ledonne et al., 2015), but there is evidence that NRG1 reduces NMDAR-induced currents in cortical pyramidal neurons ( $\mathrm{Gu}$ et al., 2005). Moreover, NRG1 influences glutamate uptake by increasing protein levels of excitatory amino acid carrier (EAAC1) in mPFC ( $\mathrm{Yu}$ et al., 2015), thus directly affecting extracellular glutamate levels.

Consistent data indicate that NRG1/ErbB signaling affects long term potentiation (LTP) of glutamatergic transmission in the hippocampus (Huang et al., 2000; Roysommuti et al., 2003; Kwon et al., 2005; Agarwal et al., 2014) and amygdala (Jiang et al., 2013; Lu et al., 2014), thus, representing a critical pathway in downscaling synaptic strength in these brain areas (Mei and Nave, 2014). To this regard, we have recently demonstrated that NRG1/ErbB signaling also modulates glutamatergic LTD in the hippocampus, since it allows mGluRI-dependent LTD at CA3-CA1 synapses (Ledonne et al., 2018). In line with this, by showing that NRG1/ErbB signaling similarly controls mGluR1mediated LTD in SNpc DA neurons, we highlight a role for 
A

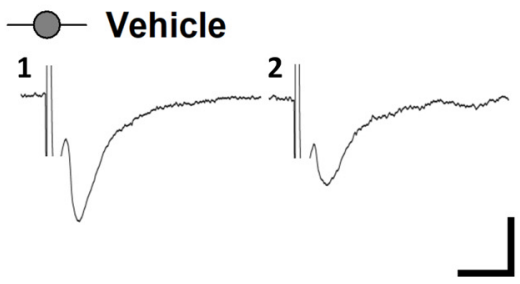

B

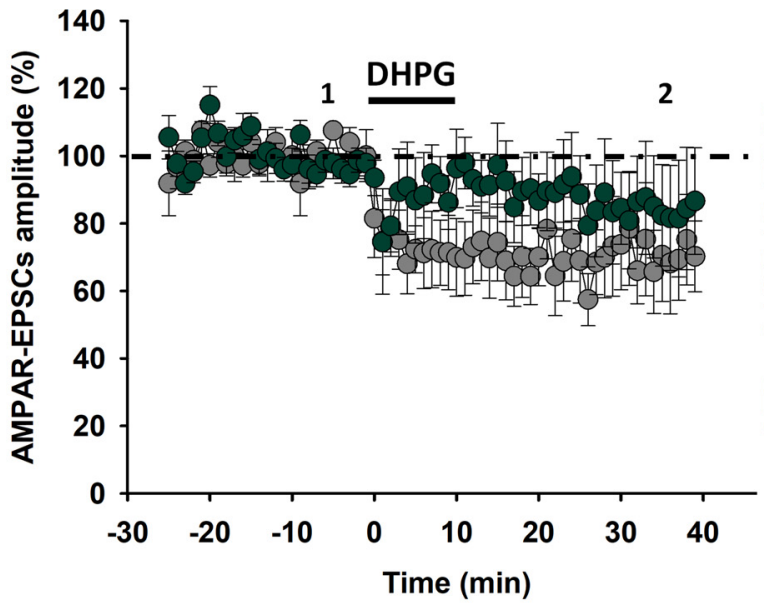

D

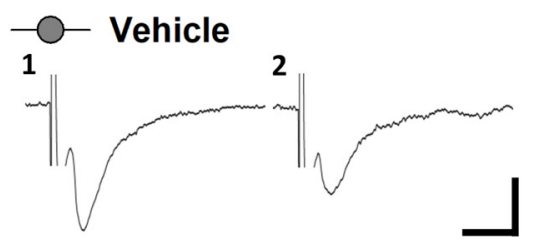

E

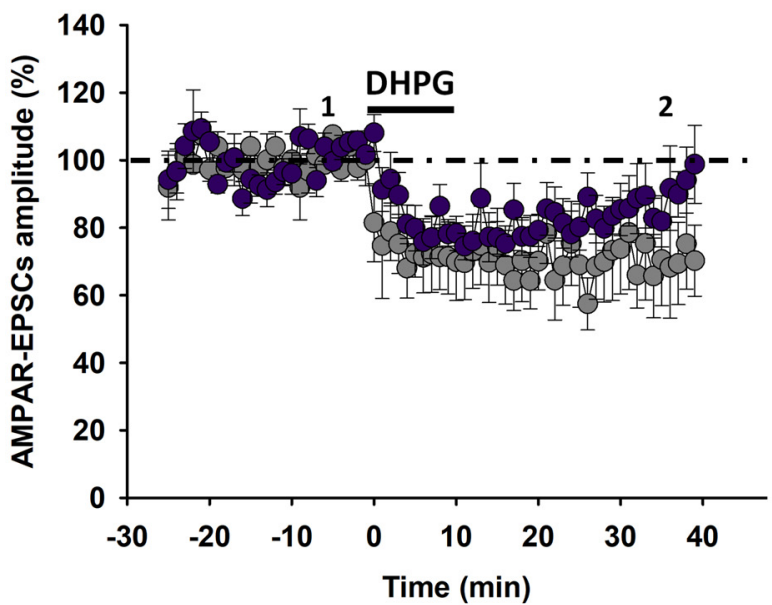

PD158780

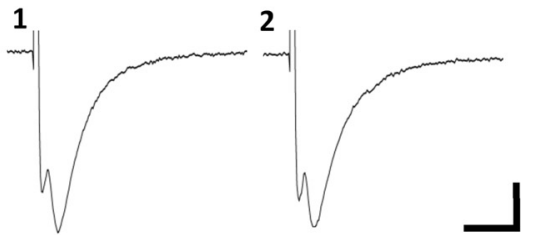

C
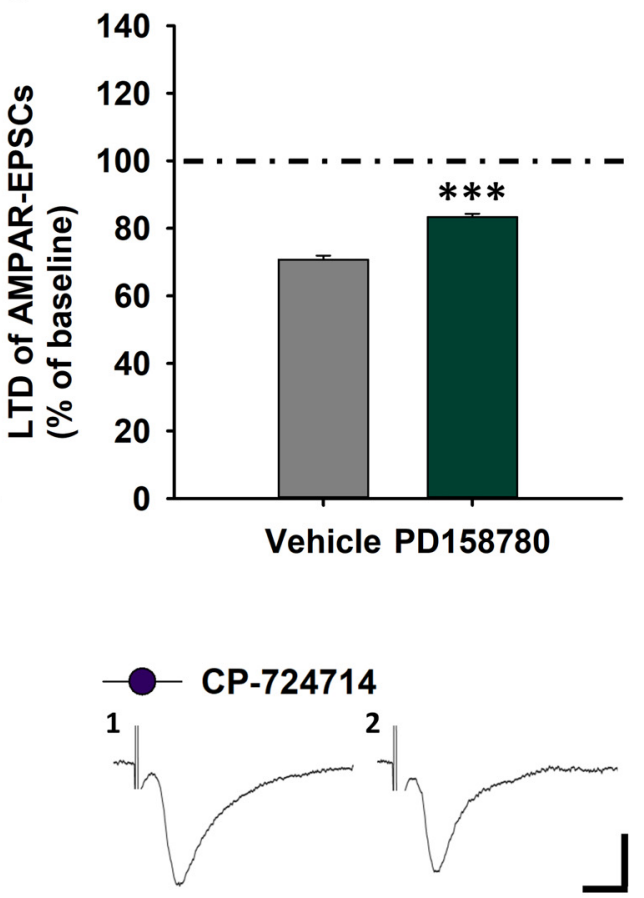

F

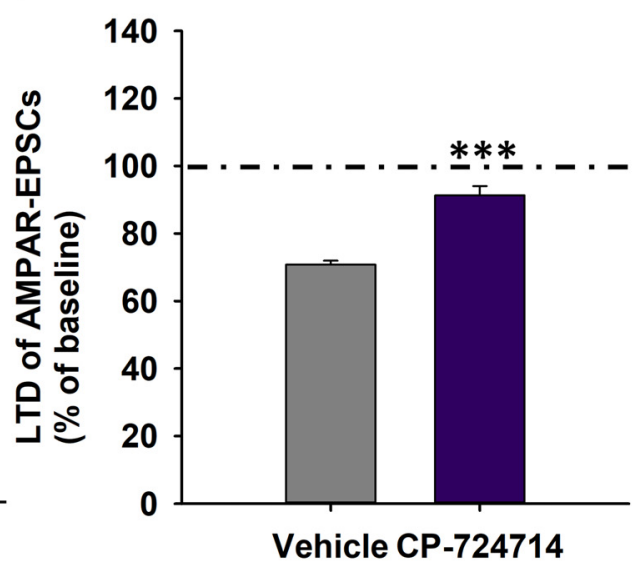

FIGURE 5 | Effects of ErbB signaling inhibition inside single SNpc DA neurons on mGluR1-dependent LTD in C57BL6 mice. (A-C) The intracellular injection of the pan-ErbB inhibitor, PD158780 (1 $\mu \mathrm{M})$, in SNpc DA neurons decreases mGluR1-dependent LTD respect to that induced by DHPG (100 $\mu$ M, 10 min) in neurons injected with its vehicle (0.0001\% DMSO). (A) Examples of AMPAR-EPSCs before (1) and after (2) DHPG application in Vehicle- and PD158780-injected cells. $\mathbf{( B , C )}$ Plots showing time course $\mathbf{( B )}$ and magnitude $\mathbf{( C )}$ of DHPG-induced LTD in Vehicle- and PD158780-injected neurons. Vehicle- $(n=5$ cells/4 mice) and PD158780-injected neurons ( $n=8$ cells/6 mice), ${ }^{* * *} p<0.001$. (D-F) Effect of the ErbB inhibitor, CP724714 (1 $\mu$ M) injected in single SNpc DA neurons on DHPG-induced LTD. (D) Representative AMPAR-EPSCs traces before (1) and after (2) application of DHPG in Vehicle- and CP724714-injected cells. (E,F) Plots of time course (E) and magnitude (F) of DHPG-induced LTD in Vehicle- and CP-724714-injected neurons. Vehicle- $(n=5$ cells/4 mice) and CP-724714-injected neurons ( $n=7$ cells/6 mice), ${ }^{* * *} p<0.001$. (A,D) Scale bar: $100 \mathrm{pA}, 5 \mathrm{~ms}$. 
A
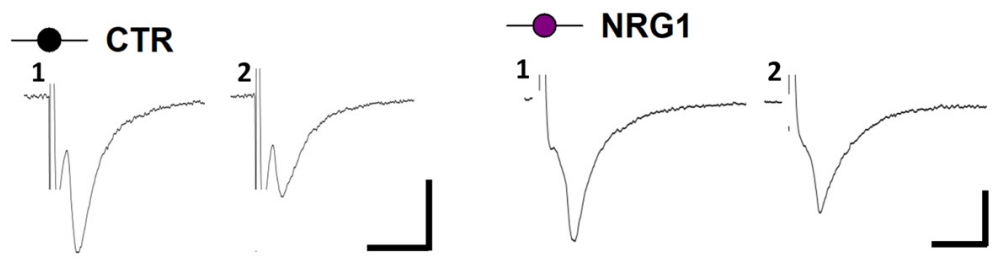

$\mathbf{B}$
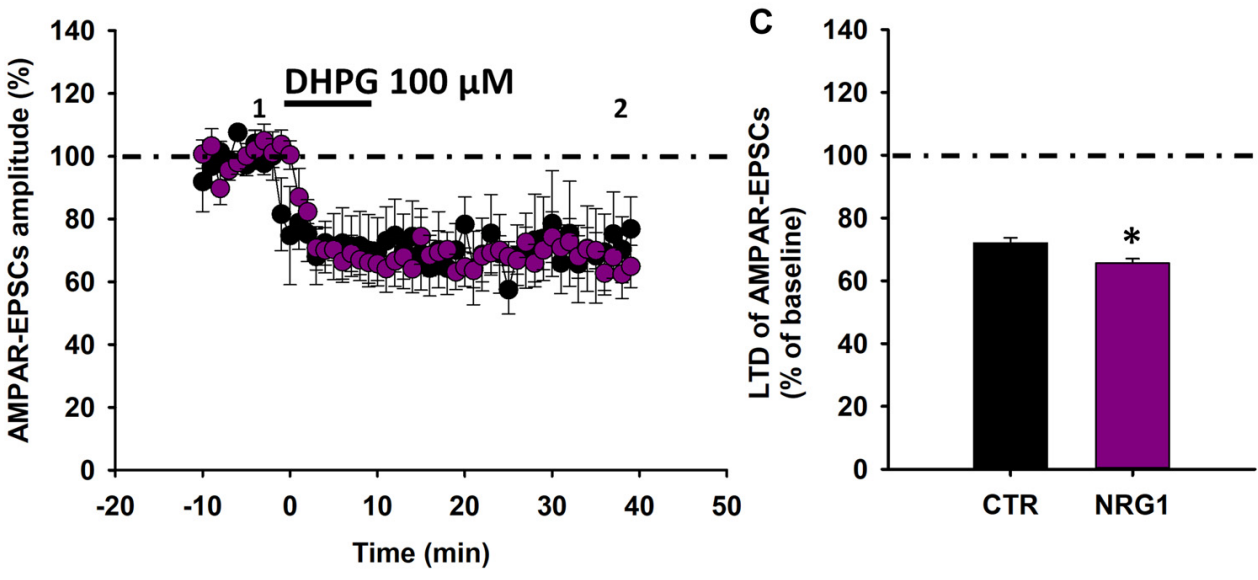

D
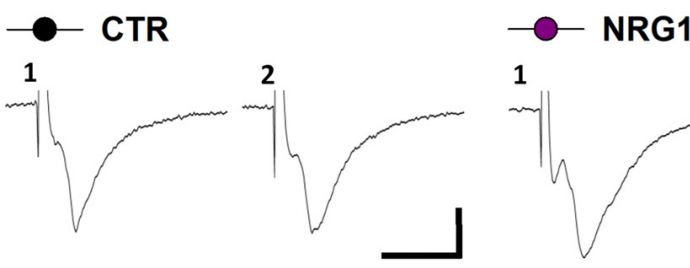

E
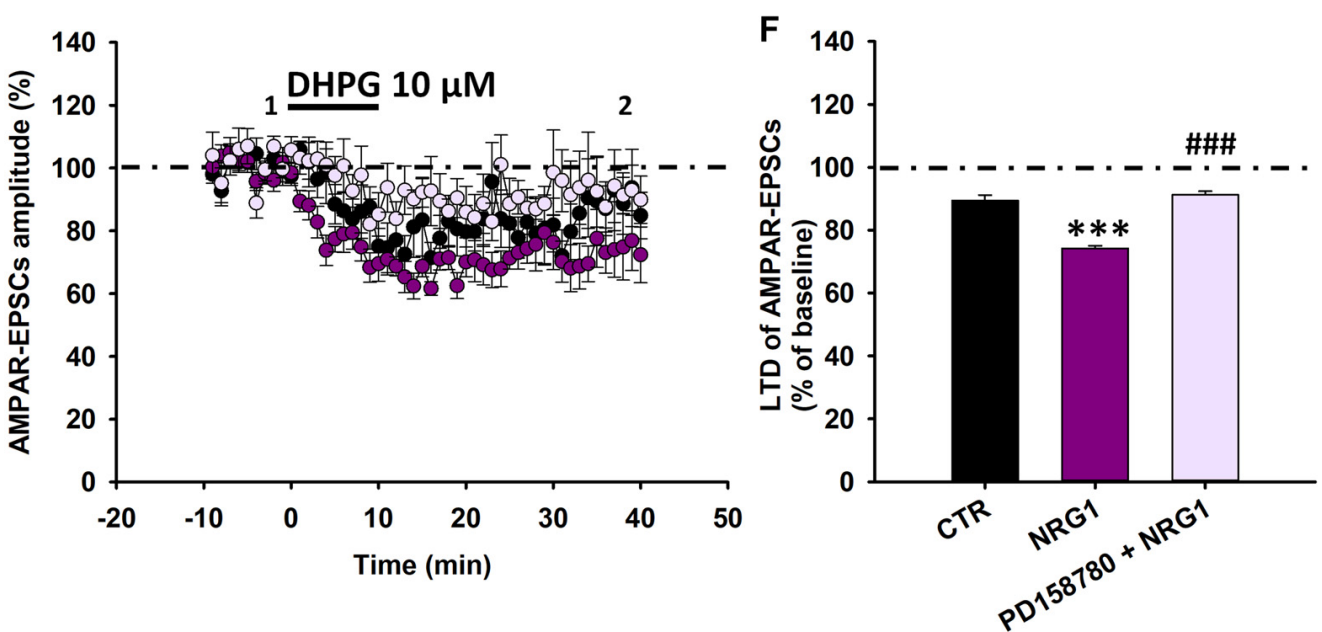

FIGURE 6 | Exogenous NRG1 application fosters mGluR1-dependent LTD in DA neurons. (A-C) Effect of exogenous NRG1 on mGluR1-dependent LTD induced by DHPG (100 $\mu \mathrm{M}, 10 \mathrm{~min})$. (A) Examples of AMPAR-EPSCs before (1) and after (2) the application of DHPG in control condition and in slices treated with NRG1 (5 $\mathrm{nM}$ $30 \mathrm{~min})$. (B,C) Plots showing time course (B) and magnitude (C) of DHPG-induced LTD. CTR ( $n=5$ cells/5 mice), NRG1 $\left(n=6\right.$ cells/5 mice), ${ }^{*} p<0.05$. (D-F) Exogenous NRG1, through ErbB activation, gates mGluR1-dependent LTD by enhancing synaptic depression induced by low DHPG concentration (10 $\mu$ M, $10 \mathrm{~min}$ ). (D) Representative traces of AMPAR-EPSCs showing the effect of DHPG (10 $\mu \mathrm{M}, 10 \mathrm{~min})$ in control condition, in slices treated with NRG1 (5 nM, $30 \mathrm{~min})$ and in slices treated with PD158780 + NRG1 (PD158780 $10 \mu \mathrm{M}$ applied 10 min before and during NRG1 $5 \mathrm{nM}, 30 \mathrm{~min}$ ). (E,F) Plots of time course (E) and magnitude (F) of DHPG-induced synaptic depression in different pharmacological conditions. CTR ( $n=9$ cells $/ 5$ mice), NRG1 ( $n=9$ cells $/ 8$ mice) and PD158780 + NRG1 $\left(n=6\right.$ cells/5 mice). ${ }^{* * *} p<0.001$ CTR vs. NRG1; \#\#\# $p 0.001$ NRG1 vs. PD158780 + NRG1, One-way ANOVA followed by Tukey's test. (A,D) Scale bar: $100 \mathrm{pA}, 5 \mathrm{~ms}$. 
NRG1/ErbB tone in the modulation of glutamatergic synaptic plasticity in midbrain DA cells.

\section{mGluR1-Dependent LTD in SNpc DA Neurons}

mGluR1/5 are key players in the modulation of excitatory synaptic strength, and their activation induces a depression of glutamatergic synaptic transmission in several brain, including hippocampus, dorsal and ventral striatum, mPFC, cerebellum and VTA (Collingridge et al., 2010; Lüscher and Huber, 2010). Notably, our data demonstrating that either prolonged pharmacological and synaptic mGluR1 activation in SNpc DA neurons induces an LTD of AMPAR-mediated synaptic transmission extend the evidence of a central role for mGluR1 in the long-term regulation of glutamatergic synaptic strength in the brain. Accordingly, there is a previous observation of an acute depressant effect of mGluRI on the excitatory transmission (Bonci et al., 1997).

Differently from SNpc, pharmacological mGluR1 activation in VTA DA neurons triggers a transient synaptic depression in naïve synapses, whereas a sustained mGluR1-dependent LTD could be induced only in synapses potentiated by psychostimulants exposure. This LTD is reliant on mGluR1induced modifications of AMPARs subunit compositions, which decrease ion channel conductances, thus weakening AMPAR-mediated transmission (Bellone and Lüscher, 2006; Mameli et al., 2007; Lüscher and Huber, 2010). Hence, our results suggest that area/neuronal population-specific differences exist in the threshold/sensitivity to mGluR1-dependent synaptic depression between SNpc and VTA DA neurons. These discrepancies could arise from different expression levels of mGluR1 in SNpc vs. VTA or to a more effective mGluR1 signaling in distinct DA neuronal populations, which allows long-lasting mGluR1-induced synaptic depression in SNpc DA cells also in naïve synapses. It should be also considered that differential experimental conditions used in previous electrophysiological recordings (mixed glutamatergic EPSCs vs. isolated AMPAR-EPSCs, or different filling electrode solutions, as well as variations in DHPG concentrations and treatment durations) might contribute to differences between mGluR1-dependent synaptic plasticity in VTA vs. SNpc DAergic neurons. Notwithstanding, a dissimilar NRG1 endogenous tone in SNpc vs. VTA might differently regulate mGluR1 levels in distinct DA neurons populations, thus producing differences in the expression of the mGluR1-induced LTD.

Regarding synaptically-induced LTD in midbrain DA neurons, previous evidence demonstrated that in SNpc/VTA DA cells the application of an LFS ( $1 \mathrm{~Hz}, 10 \mathrm{~min}$ ) paired to neuronal depolarization during stimulation $\left(\mathrm{V}_{\text {hold }}-40 \mathrm{mV}\right)$, triggers an LTD of glutamatergic transmission (mixed AMPAR- and NMDAR-activated currents; Jones et al., 2000; Thomas et al., 2000). The mechanisms underlying this form of LFS-induced LTD have been partially elucidated, indicating that it does not require activation of glutamatergic NMDA- or metabotropic receptors (Jones et al., 2000; Thomas et al., 2000). Rather, it is dependent on the activation of voltage-dependent $\mathrm{Ca}^{2+}$ channels (Thomas et al., 2000) and is negatively modulated by DA (Jones et al., 2000). In light of this previous evidence, and in the attempt to isolate a mGluR1-dependent synaptically-induced form of LTD of AMPAR-mediated transmission in SNpc DA neurons, we applied a classical LFS protocol $(1 \mathrm{~Hz}, 10 \mathrm{~min})$ in the absence of a neuronal depolarization $\left(\mathrm{V}_{\text {hold }}-70 \mathrm{mV}\right)$, and in the presence of antagonists for $\mathrm{GABA}_{\mathrm{A}}$ and $\mathrm{GABA}_{\mathrm{B}}$ as well as DA D2, and NMDA receptors. Our results show that, in these conditions, a form of synaptically-induced LTD can be elicited that is dependent on mGluR1 activation, being counteracted by a pre-treatment with a selective mGluR1 antagonist, CPCCOEt, but not with the mGluR5 inhibitor MPEP.

Notably, despite our results demonstrate that mGluR1 activation represents an important shared mechanism triggering both types of synaptic plasticity, LFS delivery might also engage other mechanisms in addition to the selective activation of mGluR1, which might eventually account for the different time course of the antagonistic effect of CPCCOEt in the different types of LTD.

Notwithstanding, we have demonstrated that mGluR1 has a central role in the modulation of glutamatergic synaptic plasticity in SNpc DA neurons, being herein involved in either pharmacological or synaptic forms of glutamatergic LTD.

\section{NRG1/ErbB-Dependent Regulation of mGluR1-Induced Synaptic Plasticity}

NRG1-activated ErbB signaling represents a critical pathway for proper mGluR1 functioning in midbrain DA neurons (Ledonne et al., 2015). Indeed, NRG1-dependent ErbB tone regulates expression levels and membrane trafficking of functional mGluR1 in SNpc DA neurons. Actually, the inhibition of endogenous ErbB signaling, by causing mGluR1 internalization, impairs mGluR1-dependent mechanisms on the nigrostriatal DA pathway, directly affecting DA neurons depolarization and in vivo striatal DA release (Ledonne et al., 2015).

In line with our previous evidence, here we have demonstrated that in SNpc DA neurons another important mGluR1 functional role (i.e., the induction of glutamatergic LTD) is compromised following ErbB inhibition, thus increasing the relevance of the interplay between NRG1/ErbB signaling and mGluR1 in these cells. Indeed, in midbrain slices treated with the pan-ErbB inhibitor, PD158780, either pharmacological or synaptic forms of mGluR1-dependent LTD (i.e., DHPG- or LFS-induced) were affected. Remarkably, our results suggest that the ErbB-dependent regulation of mGluR1-dependent LTD is a conserved mechanism controlling glutamatergic synaptic strength in midbrain DA neurons, being ErbB signaling essential for proper mGluR1-dependent LTD in different rodent species (either C57BL/6 mice or Wistar rats). Moreover, by pursuing an intracellular inhibition of ErbB receptors inside SNpc DA neurons, we confirmed that ErbB2, besides ErbB4 subunits, are involved in the modulation of mGluR1-dependent LTD, in line with a role for ErbB2-ErbB4 dimers in the regulation of mGluR1 trafficking in rat SNpc DA neurons (Ledonne et al., 2015). To this regard, we have recently reported a 
similar involvement of ErbB2 subunits in the modulation of mGluRI-dependent LTD in the hippocampus (Ledonne et al., 2018).

Besides determining the role of endogenous ErbB signaling on mGluR1-dependent LTD in SNpc DA neurons, we have analyzed whether an exogenous application of NRG1 could enhance/facilitate mGluR1-induced synaptic plasticity in DA neurons. Interestingly, we found that exogenous NRG1, through ErbB activation, fosters LTD expression in conditions of minimal mGluRI activation, thus indicating that this NRG1-dependent mechanism is involved in gating mGluR1-dependent synaptic plasticity in midbrain DA neurons.

Since we have recently demonstrated that endogenous NRG1/ErbB signaling similarly modulates mGluRI-dependent LTD in the hippocampus (Ledonne et al., 2018), the crosstalk between NRG1/ErbB signaling and mGluRI may be a shared mechanism of regulation of glutamatergic synaptic plasticity in the brain. Notably, NRG1 also impairs hippocampal mGluRI-dependent LTD of GABAergic transmission (Du et al., 2013). Thus, NRG1-dependent ErbB activation, by damaging glutamatergic LTP and favoring mGluRI-dependent glutamatergic LTD, represents a critical mechanism balancing LTP/LTD equilibrium, thus shaping strength of excitatory transmission in different brain areas.

Regarding the modulation of midbrain DA system, converging evidence suggests that NRG1/ErbB signaling acts as a positive modulator of DA transmission, since NRG1-dependent ErbB stimulation causes a hyperactivation of midbrain DA neurons by decreasing herein GABAergic inputs (Kato et al., 2010; Namba et al., 2016) and enhancing mGluR1-induced depolarizations (Ledonne et al., 2015). Thus, endogenous NRG1/ErbB signaling controls mGluR1-induced DA release in the striatum (Ledonne et al., 2015) and also shapes DA levels in projection areas by an ErbB4-dependent regulation of DAT (Skirzewski et al., 2017). Nonetheless, concerning the net contribution of the interaction between mGluR1 and ErbB receptors in the activation of midbrain DA system, it should be considered that while a brief stimulation of nigral mGluR1, which causes an inward current and fosters burst firing generation (Guatteo et al., 1999; Prisco et al., 2002), increases the phasic DA release in the striatum (Ledonne et al., 2015), a more prolonged mGluR1 activation, by inducing glutamatergic LTD, could potentially decreases the overall activity of SNpc DA cells, by rendering them less influenced by an AMPARsmediated excitatory drive. Thus, the whole contribution of the ErbB-mGluR1 functional interplay on the regulation of midbrain DA system could be dependent on the duration of stimulation of mGluR1 (brief vs. prolonged) by endogenous glutamate. For these reasons, it could be possible that the NRG1/ErbB tone, regulating mGluR1 functions contributes to an accurate adjustment of tonic/phasic DA release in the striatum

\section{Potential Physiopathological Implications and Conclusions}

mGluR1-dependent LTD has a pivotal part in learning/memory processes and behaviors involving cerebellum, hippocampus,
VTA and striatum (Collingridge et al., 2010;Lüscher and Huber, 2010). It is well established that the nigrostriatal DA pathway plays an important role in the establishment of goal-oriented behaviors, like feeding and locomotion as well as in different cognitive functions, including reward/aversion-based learning, mental flexibility and habit-formation (Da Cunha et al., 2002, 2006; Palmiter, 2008; Wise, 2009; Haber, 2014; Ilango et al., 2014; Ledonne and Mercuri, 2017). Thus, it could be hypothesized that synaptic plasticity-related mechanisms within SNpc DA cells (like mGluR1-dependent LTD) might contribute and/or underlie these brain processes.

Regarding a potential relationship between NRG1/ErbB signaling in midbrain DA neurons and learning processes potentially associated to mGluR1-dependent synaptic plasticity in $\mathrm{SNpc}$, it has been reported that a selective ErbB4 deletion in DA neurons specifically impairs spatial/working memory (Skirzewski et al., 2017), which is similarly affected by either systemic administration of mGluR1 antagonists or by a neurotoxin-induced lesion of SNpc (Da Cunha et al., 2002, 2003; Miyoshi et al., 2002; Braga et al., 2005; Hsieh et al., 2010; Sy et al., 2010). Therefore, although a direct link between ErbB-dependent regulation of nigral mGluR1 and working memory is lacking, an interplay between mGluR1-dependent synaptic plasticity and ErbB signaling in learning mechanisms concerning the nigrostriatal pathway could be conceived. Moreover, the mGluR1-dependent LTD in nigral DA neurons might be also involved in motor learning, being mGluR1 in the nigrostriatal pathway also potentially implicated in this learning process (Conn et al., 2005; Lüscher and Huber, 2010; Hodgson et al., 2011).

Notably, increasing evidence supports the contribution of mGluR1-dependent mechanisms in the pathogenesis of neurological and psychiatric disorders, such as schizophrenia, PD, addiction and autism (Ferraguti et al., 2008; Lesage and Steckler, 2010; Lüscher and Huber, 2010; Herman et al., 2012), which are characterized by alterations in midbrain DA transmission and also supposed to be linked to NRG1/ErbB dysfunctions (Han et al., 2012; Iwakura and Nawa, 2013; Mei and Nave, 2014; Ikawa et al., 2017).

Actually, mGluR1 regulates the postnatal maturation of glutamatergic synapses on VTA DA neurons (Bellone et al., 2011). An impairment of mGluR1-dependent LTD in VTA DA cells has been observed in a mouse models of autism (Bariselli et al., 2016) and it has been associated to addiction-related behaviors (Lüscher and Huber, 2010). Interestingly, genetic evidence suggests an association between altered NRG1/ErbB signaling and drug of abuse dependance (Han et al., 2012) as well as autism (Yoo et al., 2015), thus indicating that a dysfunction in ErbB-dependent regulation of mGluR1-activated LTD might be a contributing neurobiological mechanism underlying these diseases. Moreover, an unbalance of mGluR1dependent LTD, due to altered NRG1/ErbB signaling in SNpc DA neurons, could contribute to the dysfunctions in the nigrostriatal DA transmission occurring in $\mathrm{PD}$ and schizophrenia (Perez-Costas et al., 2010; Yoon et al., 2013; Ledonne and Mercuri, 2017; Weinstein et al., 2017). To this 
regard, is should be considered that NRG1 and ErbB receptors represent candidate susceptibility genes for schizophrenia (Mei and Nave, 2014), which has been also linked to an aberrant mGluR1 functioning (Gupta et al., 2005; Lesage and Steckler, 2010; Volk et al., 2010; Ayoub et al., 2012; Herman et al., 2012).

Further studies are necessary to translate the functional relevance of ErbB-dependent regulation of mGluR1-mediated LTD in SNpc DA cells in the control of DA-related behaviors and learning/memory processes, as well as to unveil the potential involvement of NRG1/mGluR1 interplay in pathogenesis of neurological and psychiatric disorders associated to dysfunction of the midbrain DA system.

\section{REFERENCES}

Abe, Y., Namba, H., Zheng, Y., and Nawa, H. (2009). In situ hybridization reveals developmental regulation of ErbB1-4 mRNA expression in mouse midbrain: implication of ErbB receptors for dopaminergic neurons. Neuroscience 161, 95-110. doi: 10.1016/j.neuroscience.2009.03.022

Agarwal, A., Zhang, M., Trembak-Duff, I., Unterbarnscheidt, T., Radyushkin, K., Dibaj, P., et al. (2014). Dysregulated expression of neuregulin-1 by cortical pyramidal neurons disrupts synaptic plasticity. Cell Rep. 8, 1130-1145. doi: 10.1016/j.celrep.2014.07.026

Ayoub, M. A., Angelicheva, D., Vile, D., Chandler, D., Morar, B., Cavanaugh, J. A., et al. (2012). Deleterious GRM1 mutations in schizophrenia. PLoS One 7:e32849. doi: 10.1371/journal.pone.0032849

Bariselli, S., Tzanoulinou, S., Glangetas, C., Prévost-Solié, C., Pucci, L., Viguié, J., et al. (2016). SHANK3 controls maturation of social reward circuits in the VTA. Nat. Neurosci. 19, 926-934. doi: 10.1038/nn.4319

Bellone, C., and Lüscher, C. (2006). Cocaine triggered AMPA receptor redistribution is reversed in vivo by mGluR-dependent long-term depression. Nat. Neurosci. 9, 636-641. doi: 10.1038/nn1682

Bellone, C., Mameli, M., and Lüscher, C. (2011). In utero exposure to cocaine delays postnatal synaptic maturation of glutamatergic transmission in the VTA. Nat. Neurosci. 14, 1439-1446. doi: 10.1038/nn.2930

Bjarnadottir, M., Misner, D. L., Haverfield-Gross, S., Bruun, S., Helgason, V. G., Stefansson, H., et al. (2007). Neuregulin 1 (NRG1) signaling through Fyn modulates NMDA receptor phosphorylation: differential synaptic function in $N R G 1^{+/-}$knock-outs compared with wild-type mice. J. Neurosci. 27, 4519-4529. doi: 10.1523/JNEUROSCI.4314-06.2007

Blum, M. (1998). A null mutation in TGF- $\alpha$ leads to a reduction in midbrain dopaminergic neurons in the substantia nigra. Nat. Neurosci. 1, 374-377. doi: $10.1038 / 1584$

Bonci, A., Grillner, P., Siniscalchi, A., Mercuri, N. B., and Bernardi, G. (1997). Glutamate metabotropic receptor agonists depress excitatory and inhibitory transmission on rat mesencephalic principal neurons. Eur. J. Neurosci. 9, 2359-2369. doi: 10.1111/j.1460-9568.1997.tb01653.x

Braga, R., Kouzmine, I., Canteras, N. S., and Da Cunha, C. (2005). Lesion of the substantia nigra pars compacta impairs delayed alternation in a Y-maze in rats. Exp. Neurol. 192, 134-141. doi: 10.1016/j.expneurol.2004.11.006

Carlsson, T., Schindler, F. R., Höllerhage, M., Depboylu, C., Arias-Carrión, O., Schnurrbusch, S., et al. (2011). Systemic administration of neuregulin$1 \beta 1$ protects dopaminergic neurons in a mouse model of Parkinson's disease. J. Neurochem. 117, 1066-1074. doi: 10.1111/j.1471-4159.2011.07284.x

Casper, D., and Blum, M. (1995). Epidermal growth factor and basic fibroblast growth factor protect dopaminergic neurons from glutamate toxicity in culture. J. Neurochem. 65, 1016-1026. doi: 10.1046/j.1471-4159.1995.65031016.x

Casper, D., Mytilineou, C., and Blum, M. (1991). EGF enhances the survival of dopamine neurons in rat embryonic mesencephalon primary cell culture. J. Neurosci. Res. 30, 372-381. doi: 10.1002/jnr.490300213

Chen, Y. J., Zhang, M., Yin, D. M., Wen, L., Ting, A., Wang, P., et al. (2010). ErbB4 in parvalbumin-positive interneurons is critical for neuregulin 1 regulation of long-term potentiation. Proc. Natl. Acad. Sci. U S A 107, 21818-21823. doi: 10.1073/pnas.1010669107

\section{AUTHOR CONTRIBUTIONS}

AL conceived the project and designed the experiments, performed and analyzed electrophysiological recordings and wrote the manuscript. NM conceived the project and wrote the manuscript.

\section{FUNDING}

This work was supported by the Brain \& Behavior Research Foundation (NARSAD 2014 Young Investigator Grant \#23004 to $\mathrm{AL}$ ), the Fulcro Foundation (to $\mathrm{NM}$ and $\mathrm{AL}$ ), and by the Italian Ministry of Health $(5 \times 1000$, anno 2016 to AL).

Collingridge, G. L., Peineau, S., Howland, J. G., and Wang, Y. T. (2010). Longterm depression in the CNS. Nat. Rev. Neurosci. 11, 459-473. doi: 10.1038/ $\operatorname{nrn} 2867$

Conn, P. J., Battaglia, G., Marino, M. J., and Nicoletti, F. (2005). Metabotropic glutamate receptors in the basal ganglia motor circuit. Nat. Rev. Neurosci. 6, 787-798. doi: 10.1038/nrn1763

Da Cunha, C., Angelucci, M. E. M., Canteras, N. S., Wonnacott, S., and Takahashi, R. N. (2002). The lesion of the rat substantia nigra pars compacta dopaminergic neurons as a model for Parkinson's disease memory disabilities. Cell. Mol. Neurobiol. 22, 227-237. doi: 10.1023/A:1020736131907

Da Cunha, C., Silva, M. H. C., Wietzikoski, S., Wietzikoski, E. C., Ferro, M. M., Kouzmine, I., et al. (2006). Place learning strategy of substantia nigra pars compacta-lesioned rats. Behav. Neurosci. 120, 1279-1284. doi: 10.1037/07357044.120.6.1279

Da Cunha, C., Wietzikoski, S., Wietzikoski, E. C., Miyoshi, E., Ferro, M. M., Anselmo-Franci, J. A., et al. (2003). Evidence for the substantia nigra pars compacta as an essential component of a memory system independent of the hippocampal memory system. Neurobiol. Learn. Mem. 79, 236-242. doi: 10.1016/s1074-7427(03)00008-x

Depboylu, C., Rösler, T. W., de Andrade, A., Oertel, W. H., and Höglinger, G. U. (2015). Systemically administered neuregulin- $1 \beta 1$ rescues nigral dopaminergic neurons via the ErbB4 receptor tyrosine kinase in MPTP mouse models of Parkinson's disease. J. Neurochem. 133, 590-597. doi: 10.1111/jnc.13026

Du, H., Kwon, I. K., and Kim, J. (2013). Neuregulin-1 impairs the long-term depression of hippocampal inhibitory synapses by facilitating the degradation of endocannabinoid 2-AG. J. Neurosci. 33, 15022-15031. doi: 10.1523/jneurosci.5833-12.2013

Erickson, S. L., O'Shea, K. S., Ghaboos, N., Loverro, L., Frantz, G., Bauer, M. et al. (1997). ErbB3 is required for normal cerebellar and cardiac development: a comparison with ErbB2-and heregulin-deficient mice. Development 124, 4999-5011.

Farkas, L. M., and Krieglstein, K. (2002). Heparin-binding epidermal growth factor-like growth factor (HB-EGF) regulates survival of midbrain dopaminergic neurons. J. Neural. Transm. 109, 267-277. doi: $10.1007 / \mathrm{s} 007020200022$

Fenster, C., Vullhorst, D., and Buonanno, A. (2012). Acute neuregulin-1 signaling influences AMPA receptor mediated responses in cultured cerebellar granule neurons. Brain Res. Bull. 87, 21-29. doi: 10.1016/j.brainresbull.2011.10.011

Ferraguti, F., Crepaldi, L., and Nicoletti, F. (2008). Metabotropic glutamate 1 receptor: current concepts and perspectives. Pharmacol. Rev. 60, 536-581. doi: 10.1124/pr.108.000166

Ferrari, G., Toffano, G., and Skaper, S. D. (1991). Epidermal growth factor exerts neurotrophic effects on dopaminergic and GABAergic CNS neurons: comparison with basic fibroblast growth factor. J. Neurosci. Res. 30, 493-497. doi: 10.1002/jnr.490300306

Fiorillo, C. D., and Williams, J. T. (1998). Glutamate mediates an inhibitory postsynaptic potential in dopamine neurons. Nature 394, 78-82. doi: $10.1038 / 27919$

Futamura, T., Kakita, A., Tohmi, M., Sotoyama, H., Takahashi, H., and Nawa, H. (2003). Neonatal perturbation of neurotrophic signaling results in abnormal sensorimotor gating and social interaction in adults: implication for 
epidermal growth factor in cognitive development. Mol. Psychiatry 8, 19-29. doi: 10.1038/sj.mp.4001138

Golani, I., Tadmor, H., Buonanno, A., Kremer, I., and Shamir, A. (2014). Disruption of the ErbB signaling in adolescence increases striatal dopamine levels and affects learning and hedonic-like behavior in the adult mouse. Eur. Neuropsychopharmacol. 24, 1808-1818. doi: 10.1016/j.euroneuro.2014.09.011

Golub, M. S., Germann, S. L., and Lloyd, K. C. (2004). Behavioral characteristics of a nervous system specific erbB4 knock-out mouse. Behav. Brain Res. 153, 159-170. doi: 10.1016/j.bbr.2003.11.010

Gu, Z., Jiang, Q., Fu, A. K., Ip, N. Y., and Yan, Z. (2005). Regulation of NMDA receptors by neuregulin signaling in prefrontal cortex. J. Neurosci. 25, 4974-4984. doi: 10.1523/jneurosci.1086-05.2005

Guatteo, E., Mercuri, N. B., Bernardi, G., and Knöpfel, T. (1999). Group I metabotropic glutamate receptors mediate an inward current in rat substantia nigra dopamine neurons that is independent from calcium mobilization. J. Neurophysiol. 82, 1974-1981. doi: 10.1152/jn.1999.82.4.1974

Gupta, D. S., McCullumsmith, R. E., Beneyto, M., Haroutunian, V., Davis, K. L., and Meador- Woodruff, J. H. (2005). Metabotropic glutamate receptor protein expression in the prefrontal cortex and striatum in schizophrenia. Synapse 57, 123-131. doi: 10.1002/syn.20164

Haber, S. N. (2014). The place of dopamine in the cortico-basal ganglia circuit. Neuroscience 282, 248-257. doi: 10.1016/j.neuroscience.2014.10.008

Han, S., Yang, B. Z., Kranzler, H. R., Oslin, D., Anton, R., Farrer, L. A., et al. (2012). Linkage analysis followed by association show NRG1 associated with cannabis dependence in African Americans. Biol. Psychiatry 72, 637-644. doi: 10.1016/j. biopsych.2012.02.038

Hanke, M., Farkas, L. M., Jakob, M., Ries, R., Pohl, J., and Sullivan, A. M. (2004). Heparin-binding epidermal growth factor-like growth factor: a component in chromaffin granules which promotes the survival of nigrostriatal dopaminergic neurones in vitro and in vivo. Neuroscience 124, 757-766. doi: 10.1016/j. neuroscience.2003.12.033

Herman, E. J., Bubser, M., Conn, P. J., and Jones, C. K. (2012). Metabotropic glutamate receptors for new treatments in schizophrenia. Handb. Exp. Pharmacol. 213, 297-365. doi: 10.1007/978-3-642-25758-2_11

Hodgson, R. A., Hyde, L. A., Guthrie, D. H., Cohen-Williams, M. E., Leach, P. T., Kazdoba, T. M., et al. (2011). Characterization of the selective mGluR1 antagonist, JNJ16259685, in rodent models of movement and coordination. Pharmacol. Biochem. Behav. 98, 181-187. doi: 10.1016/j.pbb. 2010.11.018

Hsieh, M. H., Ho, S. C., Yeh, K. Y., Pawlak, C. R., Chang, H. M., Ho, Y. J., et al. (2010). Blockade of metabotropic glutamate receptors inhibits cognition and neurodegeneration in an MPTP-induced Parkinson's disease rat model. Pharmacol. Biochem. Behav. 102, 64-71. doi: 10.1016/j.pbb.2012.03.022

Huang, Y. Z., Won, S., Ali, D. W., Wang, Q., Tanowitz, M., Du, Q. S., et al. (2000). Regulation of neuregulin signaling by PSD-95 interacting with ErbB4 at CNS synapses. Neuron 26, 443-455. doi: 10.1016/s0896-6273(00)81176-9

Hubert, G. W., Paquet, M., and Smith, Y. (2001). Differential subcellular localization of mGluR1a and mGluR5 in the rat and monkey Substantia nigra. J. Neurosci. 21, 1838-1847. doi: 10.1523/JNEUROSCI.21-06-01838.2001

Ikawa, D., Makinodan, M., Iwata, K., Ohgidani, M., Kato, T. A., Yamashita, Y., et al. (2017). Microglia derived neuregulin expression in psychiatric disorders. Brain Behav. Immun. 61, 375-385. doi: 10.1016/j.bbi.2017.01.003

Ilango, A., Kesner, A. J., Keller, K. L., Stuber, G. D., Bonci, A., and Ikemoto, S. (2014). Similar roles of substantia nigra and ventral tegmental dopamine neurons in reward and aversion. J. Neurosci. 34, 817-822. doi: 10.1523/JNEUROSCI.1703-13.2014

Iwakura, Y., and Nawa, H. (2013). ErbB1-4-dependent EGF/neuregulin signals and their cross talk in the central nervous system: pathological implications in schizophrenia and Parkinson's disease. Front. Cell. Neurosci. 7:4. doi: 10.3389/ fncel.2013.00004

Iwakura, Y., Piao, Y. S., Mizuno, M., Takei, N., Kakita, A., Takahashi, H., et al. (2005). Influences of dopaminergic lesion on epidermal growth factor-ErbB signals in Parkinson's disease and its model: neurotrophic implication in nigrostriatal neurons. J. Neurochem. 93, 974-983. doi: 10.1111/j.1471-4159. 2005.03073.x

Iyengar, S. S., and Mott, D. D. (2008). Neuregulin blocks synaptic strengthening after epileptiform activity in the rat hippocampus. Brain Res. 1208, 67-73. doi: $10.1016 /$ j.brainres.2008.02.045
Jiang, L., Emmetsberger, J., Talmage, D. A., and Role, L. W. (2013). Type III neuregulin 1 is required for multiple forms of excitatory synaptic plasticity of mouse cortico-amygdala circuits. J. Neurosci. 33, 9655-9666. doi: 10.1523/jneurosci.2888-12.2013

Jones, S., Kornblum, J. L., and Kauer, J. A. (2000). Amphetamine blocks long-term synaptic depression in the ventral tegmental area. J. Neurosci. 20, 5575-5580. doi: 10.1523/JNEUROSCI.20-15-05575.2000

Kato, T., Kasai, A., Mizuno, M., Fengyi, L., Shintani, N., Maeda, S., et al. (2010). Phenotypic characterization of transgenic mice overexpressing neuregulin-1. PLoS One 5:e14185. doi: 10.1371/journal.pone.0014185

Kramer, P. F., and Williams, J. T. (2015). Cocaine decreases metabotropic glutamate receptor mGluR1 currents in dopamine neurons by activating mGluR5. Neuropsychopharmacology 40, 2418-2424. doi: 10.1038/npp.2015.91

Kwon, O. B., Longart, M., Vullhorst, D., Hoffman, D. A., and Buonanno, A. (2005). Neuregulin-1 reverses long-term potentiation at CA1 hippocampal synapses. J. Neurosci. 25, 9378-9383. doi: 10.1523/JNEUROSCI.210005.2005

Kwon, O. B., Paredes, D., Gonzalez, C. M., Neddens, J., Hernandez, L. Vullhorst, D., et al. (2008). Neuregulin-1 regulates LTP at CA1 hippocampal synapses through activation of dopamine D4 receptors. Proc. Natl. Acad. Sci. U S A 105, 15587-15592. doi: 10.1073/pnas.0805722105

Ledonne, A., Mango, D., Bernardi, G., Berretta, N., and Mercuri, N. B. (2012). A continuous high frequency stimulation of the subthalamic nucleus determines a suppression of excitatory synaptic transmission in nigral dopaminergic neurons recorded in vitro. Exp. Neurol. 233, 292-302. doi: 10.1016/j.expneurol. 2011.10.018

Ledonne, A., Mango, D., Latagliata, E. C., Chiacchierini, G., Nobili, A., Nisticò, R., et al. (2018). Neuregulin 1/ErbB signalling modulates hippocampal mGluRIdependent LTD and object recognition memory. Pharmacol. Res. 130, 12-24. doi: 10.1016/j.phrs.2018.02.003

Ledonne, A., and Mercuri, N. B. (2017). Current concepts on the physiopathological relevance of dopaminergic receptors. Front. Cell. Neurosci. 11:27. doi: 10.3389/fncel.2017.00027

Ledonne, A., Nobili, A., Latagliata, E. C., Cavallucci, V., Guatteo, E., PuglisiAllegra, S., et al. (2015). Neuregulin 1 signalling modulates mGluR1 function in mesencephalic dopaminergic neurons. Mol. Psychiatry 20, 959-973. doi: $10.1038 / \mathrm{mp} .2014 .109$

Lesage, A., and Steckler, T. (2010). Metabotropic glutamate mGlu1 receptor stimulation and blockade: therapeutic opportunities in psychiatric illness. Eur. J. Pharmacol. 639, 2-16. doi: 10.1016/j.ejphar.2009.12.043

Lu, Y., Sun, X. D., Hou, F. Q., Bi, L. L., Yin, D. M., Liu, F., et al. (2014). Maintenance of GABAergic activity by neuregulin 1-ErbB4 in amygdala for fear memory. Neuron 84, 835-846. doi: 10.1016/j.neuron.2014.09.029

Lüscher, C., and Huber, K. M. (2010). Group 1 mGluR-dependent synaptic long-term depression (mGluR-LTD): mechanisms and implications for circuitry and disease. Neuron 65, 445-459. doi: 10.1016/j.neuron.2010.01.016

Mameli, M., Balland, B., Luján, R., and Lüscher, C. (2007). Rapid synthesis and synaptic insertion of GluR2 for mGluR-LTD in the ventral tegmental area. Science 317, 530-533. doi: 10.1126/science.1142365

Mei, L., and Nave, K. A. (2014). Neuregulin-ERBB signaling in the nervous system and neuropsychiatric diseases. Neuron 83, 27-49. doi: 10.1016/j.neuron.2014. 06.007

Miyoshi, E., Wietzikoski, S., Camplessei, M., Silveira, R., Takahashi, R. N., and Da Cunha, C. (2002). Impaired learning in a spatial working memory version and in a cued version of the water maze in rats with MPTP-induced mesencephalic dopaminergic lesions. Brain Res. Bull. 58, 41-47. doi: 10.1016/s0361-9230(02) 00754-2

Morikawa, H., Khodakhah, K., and Williams, J. T. (2003). Two intracellular pathways mediate metabotropic glutamate receptor-induced $\mathrm{Ca}^{2+}$ mobilization in dopamine neurons. J. Neurosci. 23, 149-157. doi: 10.1523/JNEUROSCI.23-01-00149.2003

Namba, H., Okubo, T., and Nawa, H. (2016). Perinatal exposure to neuregulin-1 results in disinhibition of adult midbrain dopaminergic neurons: implication in schizophrenia modeling. Sci. Rep. 6:22606. doi: 10.1038/srep22606

Namba, H., Zheng, Y., Abe, Y., and Nawa, H. (2009). Epidermal growth factor administered in the periphery influences excitatory synaptic inputs onto midbrain dopaminergic neurons in postnatal mice. Neuroscience 158, 1731-1741. doi: 10.1016/j.neuroscience.2008.10.057 
Ostenfeld, T., Horn, P., Aardal, C., Orpen, I., Caldwell, M. A., and Svendsen, C. N. (1999). Mouse epidermal growth factor-responsive neural precursor cells increase the survival and functional capacity of embryonic rat dopamine neurons in vitro. Neuroreport 10, 1985-1992. doi: 10.1097/00001756199906230-00035

Palmiter, R. D. (2008). Dopamine signaling in the dorsal striatum is essential for motivated behaviors: lessons from dopamine-deficient mice. Ann. N Y Acad. Sci. 1129, 35-46. doi: 10.1196/annals.1417.003

Perez-Costas, E., Melendez-Ferro, M., and Roberts, R. C. (2010). Basal ganglia pathology in schizophrenia: dopamine connections and anomalies. J. Neurochem. 113, 287-302. doi: 10.1111/j.1471-4159.2010.06604.x

Prisco, S., Natoli, S., Bernardi, G., and Mercuri, N. B. (2002). Group I metabotropic glutamate receptors activate burst firing in rat midbrain dopaminergic neurons. Neuropharmacology 42, 289-296. doi: 10.1016/s0028-3908(01) 00192-7

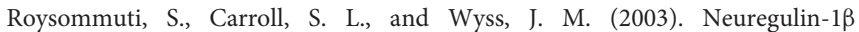
modulates in vivo entorhinal-hippocampal synaptic transmission in adult rats. Neuroscience 121, 779-785. doi: 10.1016/s0306-4522(03)00503-7

Skirzewski, M., Karavanova, I., Shamir, A., Erben, L., Garcia-Olivares, J., Shin, J. H., et al. (2017). ErbB4 signaling in dopaminergic axonal projections increases extracellular dopamine levels and regulates spatial/working memory behaviors. Mol. Psychiatry doi: 10.1038/mp.2017.132 [Epub ahead of print].

Stefansson, H., Sigurdsson, E., Steinthorsdottir, V., Bjornsdottir, S., Sigmundsson, T., Ghosh, S., et al. (2002). Neuregulin 1 and susceptibility to schizophrenia. Am. J. Hum. Genet. 71, 877-892. doi: 10.1086/342734

Steiner, H., Blum, M., Kitai, S. T., and Fedi, P. (1999). Differential expression of ErbB3 and ErbB4 neuregulin receptors in dopamine neurons and forebrain areas of the adult rat. Exp. Neurol. 159, 494-503. doi: 10.1006/exnr.1999.7163

Sy, H. N., Wu, S. L., Wang, W. F., Chen, C. H., Huang, Y. T., Liou, Y. M., et al. (2010). MPTP-induced dopaminergic degeneration and deficits in object recognition in rats are accompanied by neuroinflammation in the hippocampus. Pharmacol. Biochem. Behav. 95, 158-165. doi: 10.1016/j.pbb. 2009.12.020

Testa, C. M., Standaert, D. G., Young, A. B., and Penney, J. B. (1994). Metabotropic glutamate receptor mRNA expression in the basal ganglia of the rat. J. Neurosci. 14, 3005-3018. doi: 10.1523/JNEUROSCI.14-05-03005.1994

Thomas, M. J., Malenka, R. C., and Bonci, A. (2000). Modulation of long-term depression by dopamine in the mesolimbic system. J. Neurosci. 20, 5581-5586. doi: 10.1523/JNEUROSCI.20-15-05581.2000

Thuret, S., Alavian, K. N., Gassmann, M., Lloyd, C. K., Smits, S. M., Smidt, M. P., et al. (2004). The neuregulin receptor, ErbB4, is not required for normal development and adult maintenance of the substantia nigra pars compacta. J. Neurochem. 91, 1302-1311. doi: 10.1111/j.1471-4159.2004.02809.x

Tozzi, A., Bengtson, C. P., Longone, P., Carignani, C., Fusco, F. R., Bernardi, G., et al. (2003). Involvement of transient receptor potential-like channels in responses to mGluRI activation in midbrain dopamine neurons. Eur. J. Neurosci. 18, 2133-2145. doi: 10.1046/j.1460-9568.2003.02936.x

Volk, D. W., Egganm, S. M., and Lewism, D. A. (2010). Alterations in metabotropic glutamate receptor $1 \alpha$ and regulator of $\mathrm{G}$ protein signaling 4 in the prefrontal cortex in schizophrenia. Am. J. Psychiatry 167, 1489-1498. doi: 10.1176/appi. ajp. 2010.10030318

Volk, L., Daly, C. A., and Huber, K. M. (2006). Differential roles for group 1 mGluR subtypes in induction and expression of chemically induced hippocampal long-term depression. J. Neurophysiol. 95, 2427-2438. doi: 10.1152/jn.00 383.2005

Weinstein, J. J., Chohan, M. O., Slifstein, M., Kegeles, L. S., Moore, H., and Abi-Dargham, A. (2017). Pathway-specific dopamine abnormalities in schizophrenia. Biol. Psychiatry 81, 31-42. doi: 10.1016/j.biopsych.2016. 03.2104

Wise, R. A. (2009). Roles for nigrostriatal—not just mesocorticolimbic_dopamine in reward and addiction. Trends Neurosci. 32, 517-524. doi: 10.1016/j.tins.2009. 06.004

Yoo, H. J., Woo, R. S., Cho, S. C., Kim, B. N., Kim, J. W., Shin, M. S., et al. (2015). Genetic association analyses of neuregulin 1 gene polymorphism with endophenotype for sociality of Korean autism spectrum disorders family. Psychiatry Res. 227, 366-368. doi: 10.1016/j.psychres.2015.03.015

Yoon, J. H., Minzenberg, M. J., Raouf, S., D’Esposito, M., and Carter, C. S. (2013). Impaired prefrontal-basal ganglia functional connectivity and substantia nigra hyperactivity in schizophrenia. Biol. Psychiatry 74, 122-129. doi: 10.1016/j. biopsych.2012.11.018

Yu, H. N., Park, W. K., Nam, K. H., Song, D. Y., Kim, H. S., Baik, T. K., et al. (2015). Neuregulin 1 controls glutamate uptake by up-regulating excitatory amino acid carrier 1 (EAAC1). J. Biol. Chem 290, 20233-20244. doi: 10.1074/jbc.M114. 591867

Yurek, D. M., Zhang, L., Fletcher-Turner, A., and Seroogy, K. B. (2004). Supranigral injection of neuregulin1- $\beta$ induces striatal dopamine overflow. Brain Res. 1028, 116-119. doi: 10.1016/j.brainres.2004.08.066

Zhang, L., Fletcher-Turner, A., Marchionni, M. A., Apparsundaram, S., Lundgren, K. H., Yurek, D. M., et al. (2004). Neurotrophic and neuroprotective effects of the neuregulin glial growth factor-2 on dopaminergic neurons in rat primary midbrain cultures. J. Neurochem. 91, 1358-1368. doi: 10.1111/j.14714159.2004.02817.x

Zheng, Y., Watakabe, A., Takada, M., Kakita, A., Namba, H., Takahashi, H., et al. (2009). Expression of ErbB4 in substantia nigra dopamine neurons of monkeys and humans. Prog. Neuropsychopharmacol. Biol. Psychiatry 33, 701-706. doi: 10.1016/j.pnpbp.2009.03.021

Conflict of Interest Statement: The authors declare that the research was conducted in the absence of any commercial or financial relationships that could be construed as a potential conflict of interest.

Copyright (C) 2018 Ledonne and Mercuri. This is an open-access article distributed under the terms of the Creative Commons Attribution License (CC BY). The use, distribution or reproduction in other forums is permitted, provided the original author(s) and the copyright owner(s) are credited and that the original publication in this journal is cited, in accordance with accepted academic practice. No use, distribution or reproduction is permitted which does not comply with these terms. 